\title{
Liftoff and Transition Aerodynamics of the Ares I (A106) Launch Vehicle
}

\author{
Francis J. Capone ${ }^{1}$ \\ ViGYAN, Inc., Hampton, Virginia 23666-1325 \\ John W. Paulson, Jr. ${ }^{2}$ \\ SAIC, Inc., Newport News, Virginia 23606 \\ Gary E. Erickson ${ }^{3}$ \\ NASA Langley Research Center, Hampton, Virginia, 23681-2199
}

\begin{abstract}
An investigation has been conducted in the NASA Langley Research Center 14- by 22Foot Subsonic Wind Tunnel to obtain the liftoff and transition aerodynamics of the Ares I (A106) Crew Launch Vehicle. Data were obtained in free-air at angles of attack from $-10^{\circ}$ to $90^{\circ}$ at various roll angles and at roll angles of $0^{\circ}$ to $360^{\circ}$ at various angles of attack. In addition, tower effects were assessed by testing with and without a mobile launcher/tower at all wind azimuth angles and at various model heights to simulate the rise of the vehicle as it clears the tower on launch. The free-air data will be used for low speed high angle of attack flight simulation and as a bridge to the low angle of attack ascent database $(0.5<$ Mach $<$ 5.0) being developed with data from the Langley Unitary Plan Wind Tunnel and Boeing Polysonic Wind Tunnel. The Ares I Database Development Team will add incremental tower effects data to the free-air data to develop the database for tower clearance.
\end{abstract}

\section{Nomenclature}

$C_{N} \quad$ normal force coefficient

$C_{A} \quad$ axial force coefficient

$C_{n} \quad$ yawing moment coefficient

$C_{Y} \quad$ side force coefficient

$C_{p, \text { base }}$ base pressure coefficient

$h \quad$ vertical distance from launch tower pad to bottom of model, in.

$L \quad$ model length, in.

M free-stream Mach number

$q \quad$ free-stream dynamic pressure, $\mathrm{psi}$

$R_{n} / f t \quad$ Reynolds number per foot

$R_{n} \quad$ Reynolds number

$\alpha \quad$ angle of attack, body axis, deg

$\alpha_{v} \quad$ angle of attack, , vertical axis, deg

$\beta \quad$ angle of sideslip, deg

$\phi \quad$ roll angle, deg

$\varphi \quad$ launch tower azimuth, deg

\section{Acronyms}

\footnotetext{
${ }^{1}$ Consultant, Ares Project Office, ViGYAN, Inc., Configuration Aerodynamics Branch, Research \& Technology Directorate, and Mail Stop 499

2 Senior Engineer, Ares Project Office, SAIC, Inc., One Compass Way, R-2034, and AIAA Associate Fellow.

${ }^{3}$ Senior Research Engineer, Ares Project Office, Configuration Aerodynamics Branch, Research \& Technology Directorate, and Mail Stop 499.
} 


$\begin{array}{ll}\text { BPSWT } & \text { Boeing Polysonic Wind Tunnel } \\ \text { CFD } & \text { computational fluid dynamics } \\ \text { KSC } & \text { Kennedy Space Center } \\ \text { LaRC } & \text { Langley Research Center } \\ \text { MLP } & \text { mobile launch platform } \\ \text { NASA } & \text { National Aeronautics and Space Administration } \\ \text { SAIC } & \text { Science Applications International Corporation } \\ \text { SWT } & \text { Subsonic wind tunnel } \\ \text { TDT } & \text { Transonic Dynamics Tunnel } \\ \text { UPWT } & \text { Unitary Plan Wind Tunnel }\end{array}$

\section{Introduction}

The Ares I Aerodynamic Data Book (ref. 1) was base-lined on December 3, 2008, as part of the Ares I Preliminary Design Review. This document contained the aerodynamic and vehicle loading characteristics for the Ares I launch vehicle. These characteristics were required for simulation of the nominal and dispersed trajectories from launch through ascent and stage separation as well as powered flight of the upper stage while still in the sensible atmosphere. Also provided were characteristics of the first stage for reentry and recovery along with those of the spent upper stage for the reentry footprint for range safety.

This information was based on combinations of results from wind tunnel tests, computational fluid dynamic (CFD) calculations, engineering approximations, and, in some cases, engineering judgment. The aerodynamics for the liftoff and transition database were particularly vexing as no data existed on similar configurations, and CFD does not work well at the very low Mach numbers and high angles of attack at launch and initial free-air flight. Data from configurations such as Saturn V, Atlas, Delta and the Space Shuttle were considered along with the uncertainties for each. However, since those configurations are significantly different from Ares I it was felt that the information was not truly applicable and could at best be used as guidance. An example of the normal force from reference 1 is presented in figure 1. Because of the lack of confidence in the data, rather generous "dispersion bounds" were placed on the database. These dispersion bounds were literally proposed by the lead for the Ares I Aerodynamic Data Book, and discussed and in some cases changed by the members of the Ares I Aerodynamics Panel (A group charged with providing the Ares I aerodynamic characteristics to the Ares I Program Office and users such as the Guidance, Navigation and Control Team and the Structural Loads Team) to ultimately yield the values in the Data Book shown in the figure. The details of how this and the other aerodynamic coefficients were developed are in reference 1. However, a problem arose when these data were used in launch simulations as the results, in some crosswinds, indicated a series of clearly unacceptable cases of the vehicle striking the launch tower.

Now the team encountered a real problem in that the "approved and agreed upon data" were exceeding flight safety margins from the flight simulations, and, at that point, the team could not just say, "the values of normal force were too large" or "those generous dispersions bounds were too big, and they really should have been smaller!" Some form of "hard" data needed to be in hand to reduce the mean values and the dispersion bounds. As mentioned, CFD does not work well at these low Mach numbers and high angles of attack, so a wind tunnel test was proposed by the Aerodynamics Panel and approved by the Ares I Program Office. This test of a 1.75 percent model of the then current Ares I configuration (A106) with the current launch tower design was conducted at the NASA Langley Research Center (LaRC) $14 \times 22$ Subsonic Wind Tunnel and obtained free-air characteristics from $-10^{\circ}$ to $90^{\circ}$ angle of attack and at $0^{\circ}$ to $360^{\circ}$ of roll angle. In addition, tower effects data were obtained at all azimuth wind directions by mounting the model at $90^{\circ}$ angle of attack as if sitting on the mobile launch platform (MLP) and launch tower on the facility turntable. Effects of tower clearance were obtained by raising the model relative to the tower. Details for this will be discussed in subsequent sections of this report.

The requirement for these data was twofold. As shown in figure 2, they must provide information for the liftoff, tower clearance, and initial free-air flight at high angles of attack and low Mach numbers to improve the current data book values. In addition, the data will be a bridge to the ascent data being obtained at low angles of attack and Mach numbers from about 0.5 to 5.0 with the 1 percent models in the BPSWT and the LaRC UPWT. 
This investigation was conducted to obtain a six-component liftoff/transition aerodynamic database on a 1.75 percent scale Ares I A106 model configured with full protuberances in free air and in the presence of a 1.75 percent scale MLP. The test program consisted of two phases. The free-air testing in Phase I used a UPWT sting and mechanized roll coupling attached to a new variable pitch head adapter assembly that mounted to the existing $14 \times 22$ SWT vertical post system. MLP effects on the A106 model aerodynamics were the focus of Phase II, which used the same sting installed to a new upper vertical strut (replacing the existing 14x22 SWT hardware) to comprise a modified vertical post system. The complete results of this investigation can be found in reference 2 . Note that these are ITAR restricted.

The primary purpose of this paper is to describe this new experimental test technique and some associated test problems that were encountered during testing. It should be noted that the vertical motion hardware used in this test has been in use in 14x22 SWT for 30 years but almost exclusively for ground effect testing of both fighter/attack and transport aircraft. It has never been applied to the lift off and transition phase of flight for launch vehicles. Some results will be presented but because of restrictions on the data, they have been included only for illustrative purposes only.

\section{Wind Tunnel}

This investigation was conducted in the LaRC 14- by 22-Foot Subsonic Wind Tunnel. This is an atmospheric, low-speed tunnel with continuous control of Mach number from 0 to 0.3 . The facility has a vertical post mounting system that was designed for ground effect testing of fighter/attack and transport aircraft models. It has an angle of attack range from -10 to $50^{\circ}$ and vertical motion range from the floor of the test section to about the test section centerline.

The facility also has a boundary layer removal system to reduce the thickness of the boundary layer on the floor of the test section. This system was not working properly during the test, but the test team obtained enough information to conclude that for this model and tower installation, the minimal boundary layer effects allowed for much of the test to be conducted without the system in operation. Complete details of the facility are found in reference 3 .

\section{Model and Test Installations}

\section{A. Ares Model and Installation}

The model was a 1.75-percent scale version of the Ares I A106 design, including all protuberances that were included on the 1-percent models, which were based on the currently approved A106 outer mold line. This model, shown in figure 3 was simply a photographically scaled model, blown up from the 1-percent high-speed models to 1.75 percent. This was mounted on the Langley $14 \times 22$ SWT vertical support post with a new variable pitch head as shown in figure 4 . This head could be rotated from a $0^{\circ}$ to a $45^{\circ}$ position, allowing angles of attack from $-10^{\circ}$ to $50^{\circ}$ and then from $30^{\circ}$ to $90^{\circ}$. This provided an overlap of $20^{\circ}$ between the low and high angle of attack ranges. The high angle of attack data are the prime information for the liftoff and transition portion of the trajectory, and the low angle of attack data are the bridge to the ascent database. The UPWT roll coupling was installed upstream of the variable pitch head, allowing roll angles from $0^{\circ}$ to $360^{\circ}$ at all angles of attack. Isometric sketches of this set-up are presented in figure 5. With the vertical motion capability of the vertical strut, the center of the model could be maintained near the tunnel centerline for all angles of attack and roll.

\section{B. Launch Tower and Ares Model Installation}

The model, balance, and sting combination was also mounted on a new masthead for the top of the vertical strut such that it could be mounted at a $90^{\circ}$ angle of attack for the tower clearance portion of the test as shown in figures 6 and 7. Here the vertical motion capability allowed the model to be placed at various heights relative to the tower to simulate the rocket's position from sitting on the MLP to just clearing the tower. The 1.75 percent scale was chosen such that the model could be moved sufficiently to clear the tower but not have the nose of the model stick into the wall boundary layer on the test section ceiling. Photographs of the Ares launch vehicle at three different locations are presented in figure 8.

A feature of the model system was that the model, balance, and sting remained as a single unit throughout the test. When the variable pitch head was moved from the $0^{\circ}$ position to the $45^{\circ}$ position and when the model was 
mounted vertically on the new vertical masthead, there was no need to break down the model, ensuring that a potential source of error was eliminated.

The Kennedy Space Center (KSC) provided the Ares I MLP design details. This information was critical to properly representing the planned tower since the effects of the tower on liftoff aerodynamics in the Aero Data Book were very approximate. They were essentially taken from the Shuttle program, which was obviously based on different rocket, launch pad and tower configurations. After much discussion, the Aerodynamics Panel decided that the baseline wind tunnel tower portion of the MLP should be the current Ares I tower design, including things such as the elevator shaft and the electrical and mechanical equipment rooms. Again, after quite a bit of discussion, the Aerodynamics Panel concluded that over time the baseline tower design could and likely would change. This could possibly change the porosity of the tower as equipment rooms and hardware might be added over time. Thus, the test team had two other tower configurations modeled to change the tower porosity. Simple cover plates that could be attached to the outside of the tower affected these different porosities. One design had the plates covering onethird and the other two-thirds of the outside of the tower. These are shown in figure 9.

The orientation of the MLP and Ares I vehicle relative to the wind azimuth and vehicle roll angle affect the launch conditions. Figure 10 shows that the launch tower is on the north side of the pad complex such that a north wind (meteorological azimuth $0^{\circ}$ ) is blowing around the tower and a south wind (meteorological azimuth $180^{\circ}$ ) is blowing into the tower. The vehicle is oriented on the launch pad so that the top of the vehicle is facing to the east. This places the crew in a position for a heads down launch as is normal. Thus a west wind, blows on the bottom of the vehicle from an azimuth of $270^{\circ}$ for a roll angle of zero at $90^{\circ}$ angle of attack. A north wind yields a roll angle of $90^{\circ}$, an east wind yields a roll angle of $180^{\circ}$ and so forth. Thus roll angle and azimuth angle are out of phase by 90 degrees as will be discussed further in Section 6.2.

Since the facility turntable does not actually move $360^{\circ}$ but rather $\pm 165^{\circ}$, there was going to be a gap in the azimuth data. The set up in the tunnel was such that important north and south winds, which blow around the tower or into the tower, would be covered completely and that the east winds would not be covered based on the assumption that they would likely be similar in effects to the west winds where the wind is blowing past the tower. This assumption was valid as the west wind data can be reflected to fill the east wind gap for the final database development.

The boundary layer thickness is about 5 inches where the tower is located. Since the base of the model is 8.54 inches above the floor when the model is at the $h=0$ or $h / L=0$, it is considered to be well out of any tunnel boundary layer interference effects.

\section{Experimental Procedures}

\section{A. Force and Moment Measurements}

Instrumentation for the test consisted of the UPWT-843B six-component force and moment balance with the special calibration on the Modern Machine and Tool, Inc. single vector system (MM\&T SVS), on August 19, 2009. It should be noted that it was originally planned to use of the UT-58A/B balances which are missile balances with symmetrical load capability for roll angles from $0^{\circ}$ to $360^{\circ}$ as opposed to the airplane balances, which have a significantly larger load capability in the pitch plane rather than the yaw plane. In the end it was better to use UPWT-843B and this balance was recalibrated over the expected load range so that it reacted more like the symmetrical missile balances. In addition, a finite element analysis (FEA) of the balance indicated that there was sufficient margin for side force to be overloaded to provide a more symmetrical calibration. The load ranges for the UT-58A/B and UPWT-843B balances and the symmetrical calibration range for UPWT-843B are shown in table 1. These accuracies are a 95-percent confidence interval estimates.

\section{B. Model Attitude Measurements}

Pitch measurements were obtained using Q-Flex accelerometer mounted on the variable pitch head. The model support system attitude was corrected for sting and balance deflections due to model loads, determined from calibrations, to obtain the final model angle of attack. Roll angle was a direct measurement using the digital encoder in the UPWT Roll Coupling without further corrections.

Model height in the launch tower tests was a direct measurement from the vertical post encoders and while model attitude was fixed at a nominal $90^{\circ}$ it was corrected for the sting and balance deflections due to model loads. 


\begin{tabular}{|c|c|c|c|c|}
\hline \multicolumn{5}{|c|}{ Table 1. Balance Loads. } \\
\cline { 2 - 5 } & UT-58 & \multicolumn{3}{c|}{843} \\
\hline Component & $\begin{array}{c}\text { Max Balance } \\
\text { Loads }\end{array}$ & $\begin{array}{c}\text { Max Balance } \\
\text { Loads }\end{array}$ & $\begin{array}{c}\text { Max Calibrated } \\
\text { Loads }\end{array}$ & $\begin{array}{c}\text { Accuracy } \\
\% \text { F.S. }\end{array}$ \\
\hline Normal & $300 \mathrm{lbs}$ & $800 \mathrm{lbs}$ & $400 \mathrm{lbs}$ & 0.06 \\
\hline Axial & $75 \mathrm{lbs}$ & $250 \mathrm{lbs}$ & $100 \mathrm{lbs}$ & 0.14 \\
\hline Pitch & $1200 \mathrm{in}-\mathrm{lbs}$ & $2500 \mathrm{in}-\mathrm{lbs}$ & $1250 \mathrm{in}-\mathrm{lbs}$ & 0.03 \\
\hline Roll & $300 \mathrm{in}-\mathrm{lbs}$ & $1000 \mathrm{in}-\mathrm{lbs}$ & $300 \mathrm{in}-\mathrm{lbs}$ & 0.41 \\
\hline Yaw & $1200 \mathrm{in}-\mathrm{lbs}$ & $1000 \mathrm{in}-\mathrm{lbs}$ & $1250 \mathrm{in}-\mathrm{lbs}$ & 0.05 \\
\hline Side & $300 \mathrm{lbs}$ & $500 \mathrm{lbs}$ & $400 \mathrm{lbs}$ & 0.06 \\
\hline
\end{tabular}

\section{Data Adjustments and Discussion of Base Pressure Measurement}

Base pressure corrections were applied to the data based upon a pair of measured model cavity pressures. These two pressures were averaged and then assumed to apply to the base area of the model. This allows axial force to be corrected so that simulation data will be free of the base effects on axial force so the base pressures based on trajectory and power effects can be properly model in the actual simulations. This is normally a straightforward process and was so for the high angle of attack free-air data and the tower affect data. However, as shown in figure 11 , something was in error for much of the low angle of attack free-air data. It was impossible to determine exactly what caused the base pressures to vary so much but it was assumed to be issues with the pressure tubing when rolling the model $360^{\circ}$. The figures show the wide variation of base pressure and the "misalignment" between the low and high angle of attack results. However, there were some runs that "looked good," matched some previous data trends (refs. 4 and 5) and "lined up" with the high angle of attack results. It was decided that the best solution was to create an average base pressure based on results at zero roll angle and apply that correction for all roll angles. This of course presumes that roll angle effects on base pressure are small and where we believe we have good data this is so. There would then be a dispersion bound placed on the average base pressure which would be large enough to include the observed roll angle effects but would not include the "really questionable" points shown. This is shown in figure 12. In the scheme of launch simulation the effects of base pressure are very small when concerned with the possibility of tower strikes $\left(C_{N}, C_{Y}\right.$ and $C_{M}$ are the drivers) and so the effects of any errors in this data set caused by this approach are thought to be minuscule.

\section{Tests}

\section{A. Method of Obtaining Data}

This investigation was conducted over a range of dynamic pressures from $10 \mathrm{psf}$ to $120 \mathrm{psf}$. The nominal test conditions are given in table 3. Free air or transition mode data were obtained in angle of attack sweeps at constant roll angles and in roll sweeps at constant angles of attack at $q=40 \mathrm{psf}$ and $80 \mathrm{psf}$. This gives a significant range of angle of attack and sideslip as shown in figure 13. Note that there are some gaps in the plot where data were not obtained and this will be discussed in a subsequent section. Tower effects data was obtained by rotating the facility turntable through azimuth angles with the Ares I model at constant heights above the MLP and with the model at various heights above the MLP at constant azimuth angles. 


\begin{tabular}{|c|c|c|c|}
\hline \multicolumn{4}{|c|}{ Table 2. Nominal test conditions. } \\
\hline$q, \mathrm{psf}$ & $M$ & $R n / \mathrm{ft}$ & $R n$ \\
\hline 10.0 & 0.082 & 0.57 & 0.12 \\
\hline 20.1 & 0.117 & 0.80 & 0.17 \\
\hline 30.1 & 0.143 & 1.00 & 0.21 \\
\hline 40.1 & 0.165 & 1.13 & 0.24 \\
\hline 50.1 & 0.185 & 1.25 & 0.27 \\
\hline 60.1 & 0.204 & 1.37 & 0.29 \\
\hline 80.0 & 0.236 & 1.57 & 0.33 \\
\hline 100.1 & 0.266 & 1.75 & 0.37 \\
\hline 120.0 & 0.292 & 1.90 & 0.41 \\
\hline
\end{tabular}

\section{B. Boundary Layer Transition}

One of the concerns from the beginning was whether the model BL would be laminar or turbulent, as this can have profound effects on the resulting aerodynamics. In an effort to ensure turbulent flow a series of runs were initially conducted with a clean model and several different grit patterns, shown in figures 14 and 15, where the tunnel dynamic pressure and hence Reynolds number were varied from low values up to nearly the maximum of the tunnel capability. Figure 16 shows that the aerodynamic coefficients vary rather wildly on the clean configuration and at low Reynolds numbers ( $q$ less than about $40 \mathrm{psf}$ ) but tend to flatten out at higher Reynolds numbers for the gritted models. Based on significant research by Dr. Robert M. Hall ${ }^{6}$, two strips of number 80 grit at $54^{\circ}$ away from the stagnation line on the windward side gives a good approximation of the proper boundary layer state. The issue here is when the model is rolled two strips clearly cannot be used at other than at roll angle of $0^{\circ}$. The question then is how many strips might be required as the model is rolled in order to keep the stagnation line properly between two strips? This quickly leads to a conclusion that "many" would be needed and in the limit this is simply a continuous distribution of strips or a uniform distribution of grit.

Work on the Ares I-X ground winds load test in TDT (ref. 7) and published results (ref. 8) indicated a "uniform" grit could be applied to the model for proper boundary layer transition. In 14x22, both 220 and 80 grits were applied as shown in figures 14 and 15 . Figure 16 clearly indicates that the three grit patterns are superior to the clean model. One of the potential problems with uniform grit applications is that it can be over applied and can remove too much energy from the boundary layer yielding excessively high loads, especially for normal force at high angles of attack. Note that the uniform 80 grit does yield higher $C_{N}$ than that of the 220 grit. To the authors, it appeared that the 80 grit had been applied a bit "over generously" and the technicians were asked to reduce the density and improve the uniformity of the grit application. As shown in figure 16, this seemed to bring the normal force back in line with the results for the 220 grit. At this point, without launching into a lengthy "grit study" it was agreed that the "cleaned up 80 grit" was "good enough" and we proceeded with the testing at dynamic pressures above $40 \mathrm{psf}$ without making any attempts to confirm boundary layer transition. Thus with careful handling of the model all free-air and tower effects testing was conducted with the grit pattern on the model as it was at the end of the BL transition phase of the investigation.

After completing these studies at dynamic pressures from 10 to $120 \mathrm{psf}$, testing at $q$ of 100 to $120 \mathrm{psf}$ was not necessary for boundary layer transition or from model system vibration considerations. Therefore all testing was conducted at two dynamic pressures of 40 and 80 psf unless as in some of the tower testing, we again ran " $q$ sweeps."

\section{Data Repeatability}

Many repeat runs were made during this investigation at selected test conditions during pitch sweeps, roll sweeps, $q$ sweeps, and azimuth sweeps. It should be noted that about 17-percent of the 425 data runs were dedicated to repeat runs. In general this data repeated very well (figs. 17 to 21). Some issues existed for some runs where the low and high angles of attack overlapped regions in the $30^{\circ}$ to $50^{\circ}$ range did not line up as well as was hoped. However, this unresolved discrepancy, due to model dynamics, hysteresis, or the like, in a region with separated vortex flows, was included in the data set given to the Database Development Team, and the uncertainty bounds applied to the simulation database in this region were simply increased. Trajectory analysis will determine if this area is a problem or not, and if so, then a plan to examine this region in a subsequent test may be required. 
It should be noted that the test was generally conducted at both 40 and $80 \mathrm{psf}$. This effectively gave a repeat run at every test point and proved especially valuable because often, when model vibrations prevented testing at one condition, the other was all right. Thus, among pitch runs and roll runs and the two- $q$ settings, almost every desired test point ultimately was covered. An example of the excellent correlation obtained between the two dynamic pressures is presented in figure 22 .

\section{Test Results And Discussion}

\section{A. Free-air or Transition Mode Results}

The free-air portion of the test was conducted in two phases. First was the high angle of attack phase with the variable pitch head in the $45^{\circ}$ position where angle of attack ranged from $30^{\circ}$ to $90^{\circ}$. This was followed by the low angle of attack phase with the variable pitch head in the $0^{\circ}$ position where angle of attack ranged from $-10^{\circ}$ to $50^{\circ}$. During these phases pitch sweeps were taken at fixed roll angles, then roll sweeps were taken at fixed angles of attack.

It was quickly discovered that, at some test conditions, the model experienced severe vibrations that prevented testing as shown in figures 23 and 24 where normal force coefficients about the body axis are presented at two dynamic pressures. Vibrations occurred over a wide range of tunnel conditions and model attitudes and, in general, were centered in the angle of attack range around $50^{\circ}$, but this was by no means the only place where these happened. In some of the data plots, gaps are seen where these vibrations prevented testing. As can be seen in these two plots, gaps in one are not present in the other. This, as mentioned earlier, meant that almost every desired test point was obtained at one dynamic pressure or another. Also as mentioned earlier, the matching of the high and low data in the $30^{\circ}$ to $50^{\circ}$ range was not always good. This may have been from unsteady flow causing the vibrations and/or hysteresis effects that were not fully investigated because of vibration problems. The Database Team addressed these differences by increasing the uncertainty in this region.

In an effort to determine a cause for these vibrations, the facility dynamic data acquisition system, at times, detected a $7.5 \mathrm{~Hz}$ signal in the aerodynamic loads from an undetermined source. During a model change, the test team conducted tests where the model was struck with a rubber mallet. The response frequency of the system to those strikes was between 6.9 and $7.2 \mathrm{~Hz}$, depending on whether the pitch or yaw plane was excited. The test team surmised that a forcing function frequency and response frequency that are so close together could coalesce to yield significant vibrations. As a lesson learned for any future testing, the model response frequency should be detuned from the facility's airstream frequency.

One problem with trying to analyze body axis force and moment coefficients obtained over the very extensive range of angle of attack is that sideslip angle is not constant. Thus it is usually convenient to convert the forces and moments from the body axis coordinate system to the vertical missile axis system. The vertical missile axis system is defined as missile axis system where the $\mathrm{z}$-axis (normal force direction) always points up in the vertical direction. The conversion of the force and moment coefficients is a function only of the model roll axis. An example of normal force coefficients about the vertical axis system is presented in figure 25 for roll angles from $195^{\circ}$ to $270^{\circ}$ (test data taken in the third quadrant) at $q=40 \mathrm{psf}$. Note that there are similar results for the other three quadrants at $q=40 \mathrm{psf}$ and data are also available for all four quadrants at a $q=80 \mathrm{psf}$.

When all of the normal force data are averaged the resulting $C_{N}$ can be compared with the $C_{N}$ from the Data Book along with the experimentally derived upper and lower bounds. As shown in figure 26, these results illustrate that the trend in $C_{N}$ is similar to that proposed in the original Aerodynamic Data Book with the main difference being that this average experimental $C_{N}$ is about 17-percent lower than the Data Book at angles of attack above $70^{\circ}$. This experimental value of $C_{N}$ at $\alpha_{\mathrm{v}}=90^{\circ}$ is about the same as that obtained in the Ares I-X Ground Wind Loads testing in the LaRC TDT. The experimental data upper and lower bounds were determined in a rigorous uncertainty analysis ${ }^{9}$. There is a significant reduction in the highest possible values of $C_{N}$ using Data Book results compared to those from the experiment. This is a major development as the predicted high $C_{N}$ was driving the simulations to indicate tower strikes. With hard information for calculating bounds, it is seen that the level of uncertainty in the middle angle of attack range is actually increased over that from the Data Book; however, this is not an issue in launch simulations for tower clearance.

Variations in the aerodynamic coefficients with roll angle (fig. 27) are similar to those observed during previous higher Mach number testing in that they are clearly functions of the position of the various protuberances relative to the free stream flow. It is not possible, without serious flow visualization and/or some way to accurately determine actual protuberance loads (not likely at these scales), to determine which protuberance or protuberances are the drivers, but these trends are consistent and repeatable. It is likely that for the longitudinal data, the peaks in 
$C_{Y}$ at about $0^{\circ}$ and $180^{\circ}$ in figure 27 occur when the LH2 line and the systems tunnel are at the 9 and 3 o'clock positions relative to the free stream and act as rather poor lifting surfaces. "Poor" being relative to a wing but with the relatively long moment arms to the vehicle centerline and with relatively weak roll control authority for Ares I, these protuberance loads can produce moments that, depending on the flight condition, could be a problem for vehicle control.

\section{B. Tower or Liftoff Mode Results}

The effects of the tower on the aerodynamics of the launch vehicle are shown in figures 28 and 29. During testing, as a first check on the validity of this tower data, the model was tested mounted on the new vertical strut head at $90^{\circ}$ angle of attack and at the maximum height to tower ratio of 0.97 through a $360^{\circ}$ azimuth sweep. This data compared with that from a free-air roll sweep at $90^{\circ}$ angle of attack should be identical (fig. 28). They are very close, except they are out of phase by $90^{\circ}$ because roll angle is based relative to the configuration and azimuth is based on the points of the compass. That is, an east wind at $90^{\circ}$ azimuth corresponds to a roll angle of $180^{\circ}$ as the east wind is blowing on the top of the rocket as if it were rolled inverted so that the pilots were heads down or the normal launch attitude for a due east trajectory. This is shown pictorially in figure 10.

It can be seen in the data of figure 29 that there are interference effects from the tower that are a function of azimuth. The largest effects on side force appear when the wind is from the northwest to northeast, as would be expected as the wind is blowing around the tower. Also there is an effect when a south wind is blowing into the tower. Effects on normal force appear to be largest when the wind is from the east or west, and one can envision an acceleration of the wind around the tower increasing the normal loading.

As mentioned, previous simulations using the original database indicated tower strikes with south winds pushing the vehicle into the tower. It is, in fact, the vector sum of $C_{N}$ and $C_{Y}$ yields the resultant force on the vehicle as it begins to climb on liftoff. It turns out that the worst case actually occurs for a wind from the southeast at about $135^{\circ}$. However, these values are significantly lower than those in the original data book so it would seem that the likelihood of tower strikes should be significantly reduced. In addition, the tower effects diminish as the height of the model increases and approaches the free-air results at $h / L=0.97$, or when the model has almost cleared the tower.

Part of this investigation was intended to provide information on various levels of tower porosity. Depending on the floor chosen and the aspect for viewing the tower, the porosity can vary from about 60 percent (open area to total projected area) to about 10 percent (for a floor with the elevator shaft and an equipment room). It is difficult to define single tower porosity. The test team chose to use the one-third and two-thirds cover plates to vary the tower porosity from that of the baseline tower by covering up one-third and then two-thirds of the area of each side of the tower. Data presented in figures 30 and 31 indicates that while the cover plates follow the trend of increasing porosity with clearly measurable effects, these effects are significantly smaller than the effects from the baseline tower. This makes sense, as the baseline tower is open to wind flow. Small changes in tower porosity have only a secondary effect.

These tower effects were obtained under steady state conditions with a fixed wind azimuth and a fixed model height yielding a constant angle of attack on the model of $90^{\circ}$. This, of course, is not really the condition encountered on launch as the wind azimuth can be variable, and, of potentially more concern, the angle of attack is $90^{\circ}$ only at the instant of liftoff. Since the vehicle angle of attack is the vector sum of the crosswind and the vehicle forward velocities, angle of attack decreases quickly as the vehicle accelerates at 1.4 times gravity. By the time the tower is cleared, angle of attack is reduced to about $20^{\circ}$ in a $40 \mathrm{kt}$ crosswind. Because of testing limitations, nothing can be done about this. The test team could not move the model fast enough to obtain dynamic data at anything like the correct angles of attack. The database team understands this, and they decided to develop incremental data calculated with and without the tower present at the various model heights. These increments are then added to the free-air data to build the launch database. It is doubtful that this will cause concerns in simulation. However, it is clearly an assumption that an increment obtained at $90^{\circ}$ and $h / L$ of 0.5 will be correct even though the launch angle of attack (at 1.4 times gravity and a $40 \mathrm{kt}$ cross wind) at that point is actually about $30^{\circ}$. 


\section{Concluding Remarks}

A test was conducted in the LaRC 14- by 22-Foot Subsonic Wind Tunnel to obtain the liftoff and transition aerodynamics of the Ares I (A106) launch vehicle. Data were obtained in free air at angles of attack from $-10^{\circ}$ to $90^{\circ}$ at roll angles of $0^{\circ}$ to $360^{\circ}$ at various angles of attack. In addition, tower effects were obtained by testing with and without a mobile launcher/tower at all wind azimuth angles and at various model heights to simulate the rise of the vehicle as it clears the tower on launch.

The free-air data will be used for a low speed, high angle of attack database for flight simulation and as a bridge to the bottom end of the low angle of attack ascent database $(0.5<$ Mach $<5.0)$ being developed with data from the UPWT and BPSWT. Incremental tower effects data will be added to the free-air data to develop the database for tower clearance.

To the authors' knowledge, this represents the first time that such a test has been conducted to obtain tower clearance data for launch simulation.

\section{References}

1. Ares I Aerodynamic Data Book: CxP 72214, December 3, 2008.

2. Capone, Francis J.; Paulson, John W. Jr.; Liftoff and Transition Aerodynamics of the Ares I (A106) Launch Vehicle. NASA ARES-AD-TA-0019, 2010. (ITAR Restricted)

3. Gentry, G. I.; Quinto, P. F.; Gatlin, G. M.; and Applin, Z. T.: The Langley 14- by 22-Foot Subsonic Tunnel: Description, Flow Characteristics and Guide for Users. NASA TP-3008, 1990.

4. Capone, Francis J.; and Stumbris, Gunnars: Transonic Longitudinal Aerodynamic Characteristics of Five Cone Cylinder-Flare Bodies of Revolution. NASA TM X-963, 1964.

5. Capone, Francis J.: A Summary of Base Pressure Measurements on Cone-Cylinder Bodies in the Langley 16-Foot Transonic Tunnel. NASA LWP-944, 1971.

6. Hall, R. M.: and Banks, D. W.: Progress in Developing Gritting Techniques for High Angle of Attack Flows. AIAA-94-0169, January 10, 1994.

7. Keller, Donald F.: Test Summary for Ground Wind Loads Checkout Model Transonic Dynamics Tunnel Test 595, Ares-AE-TA-0001, 3 August 2007.

8. Szechenyi, Edmond: Supercritical Reynolds Number Simulation for Two-dimensional Flow over Circular Cylinders, J. Fluid Mechanics, 1975, vol. 70, part 3, pp 529-542.

9. Hanke, Jeremy L.; and Favaregh, Amber: Uncertainty Quantification and Modeling for the Ares I A106 Liftoff/Transition Aerodynamic Database. Ares-AD-TA-0016, 2010. 


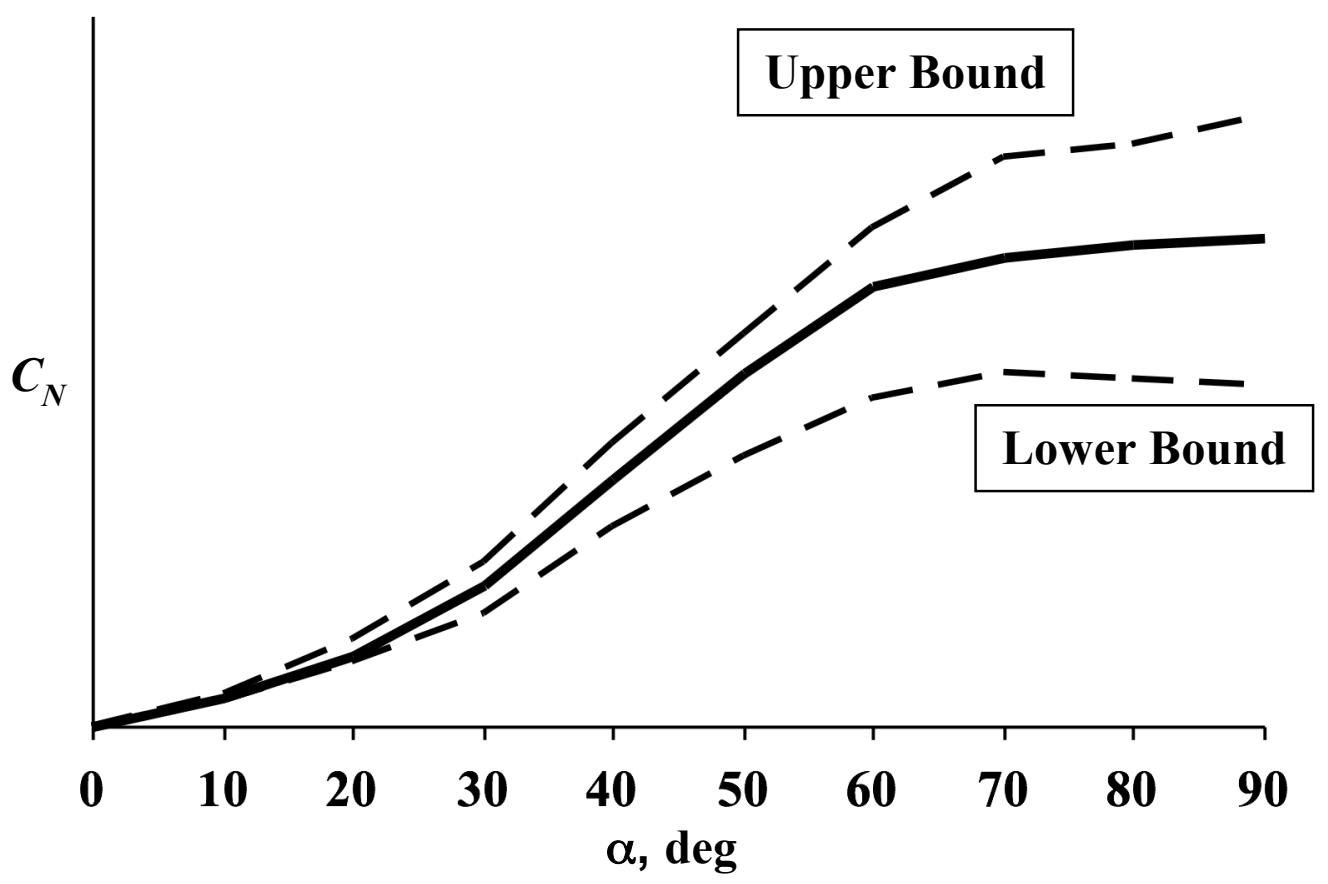

Figure 1. Predicted vehicle normal force coefficient

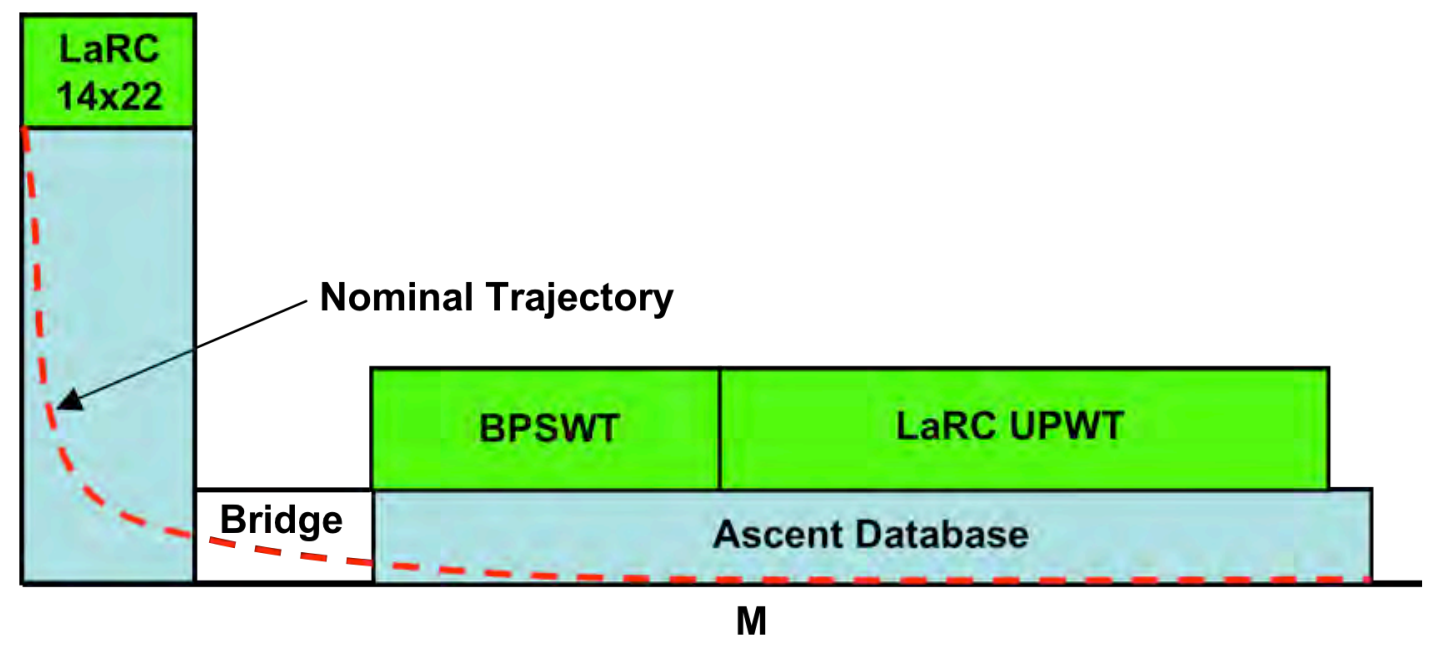

Figure 2. Definition of Ares I data bases. 

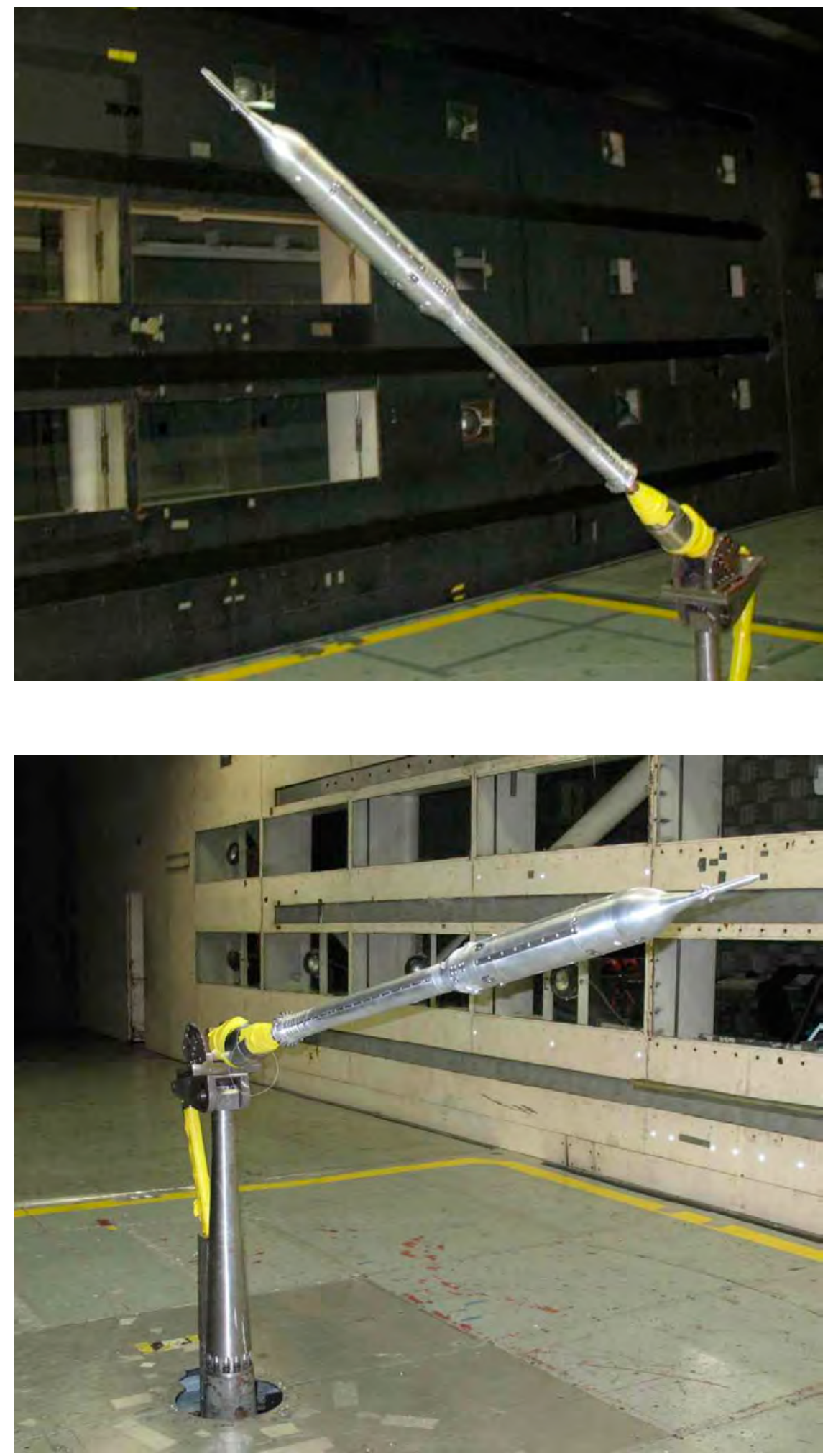

Figure 3. Ares 1 model installed in the transition mode. 


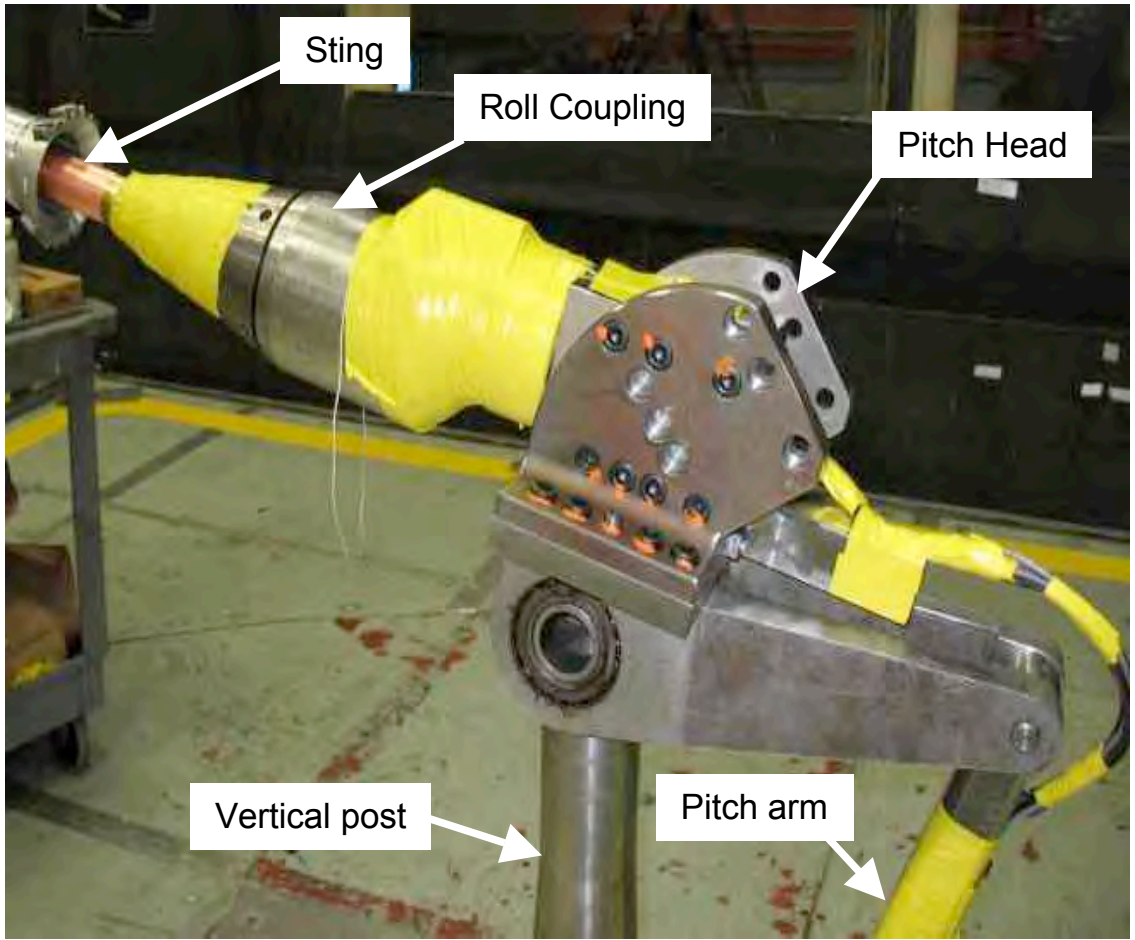

Figure 4. Details of the transition mode installation.
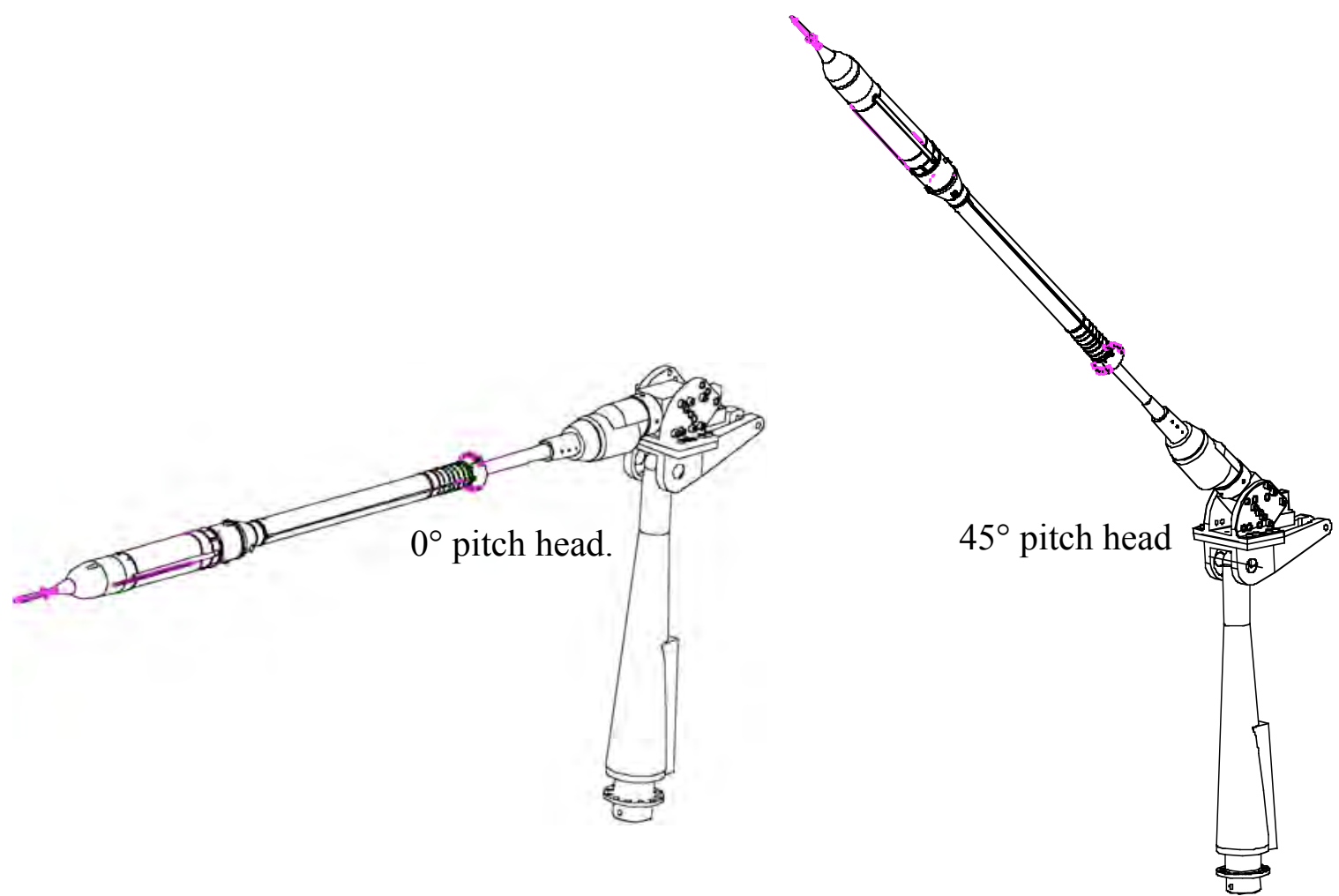

Figure 5. Isometric sketches of model installed in the transition mode. 


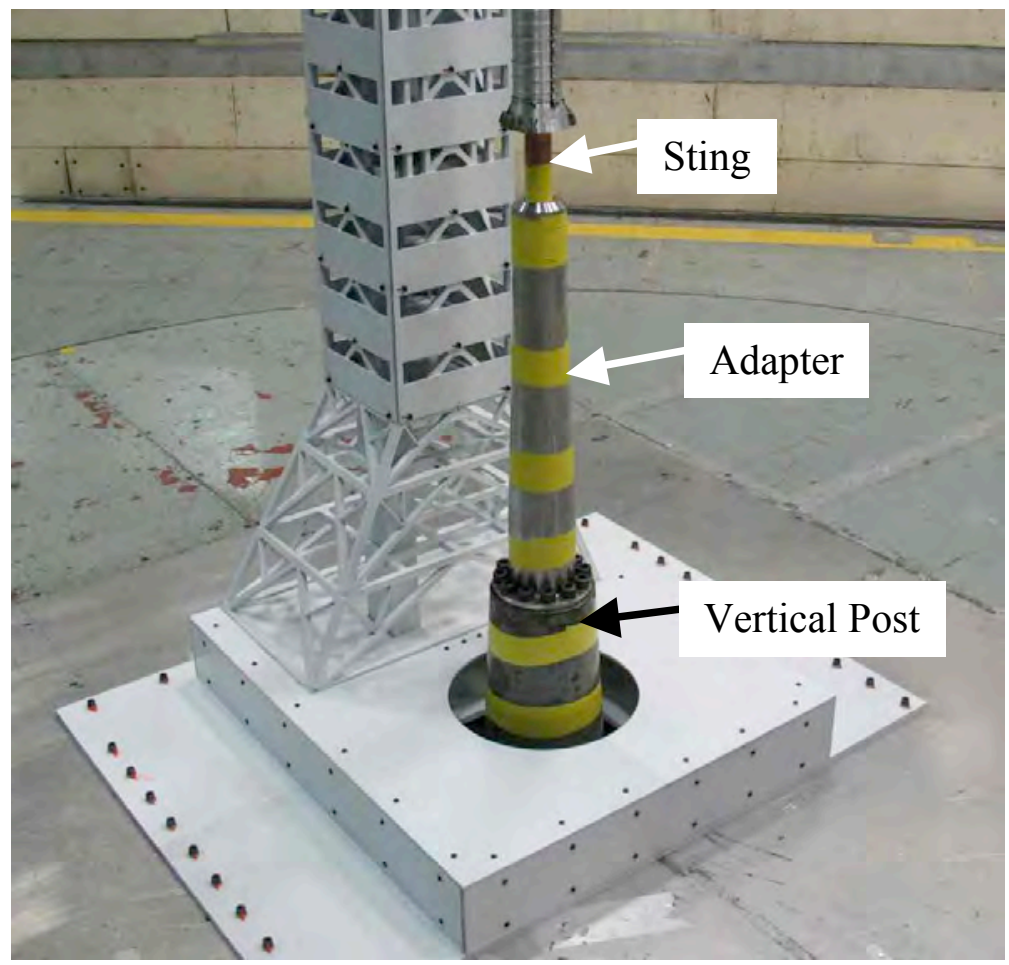

Figure 6. Photograph showing details of the liftoff mode installation.

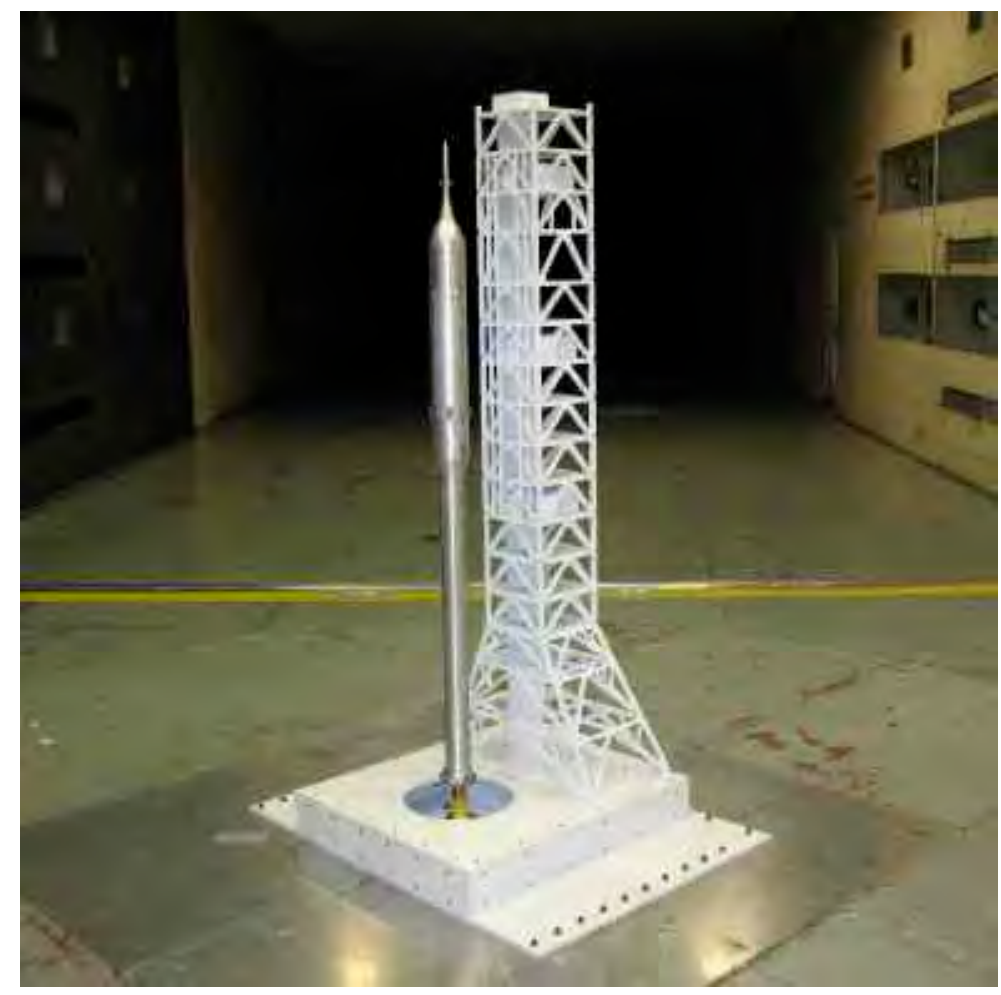

Figure 7. Photograph showing Ares with launch tower. 

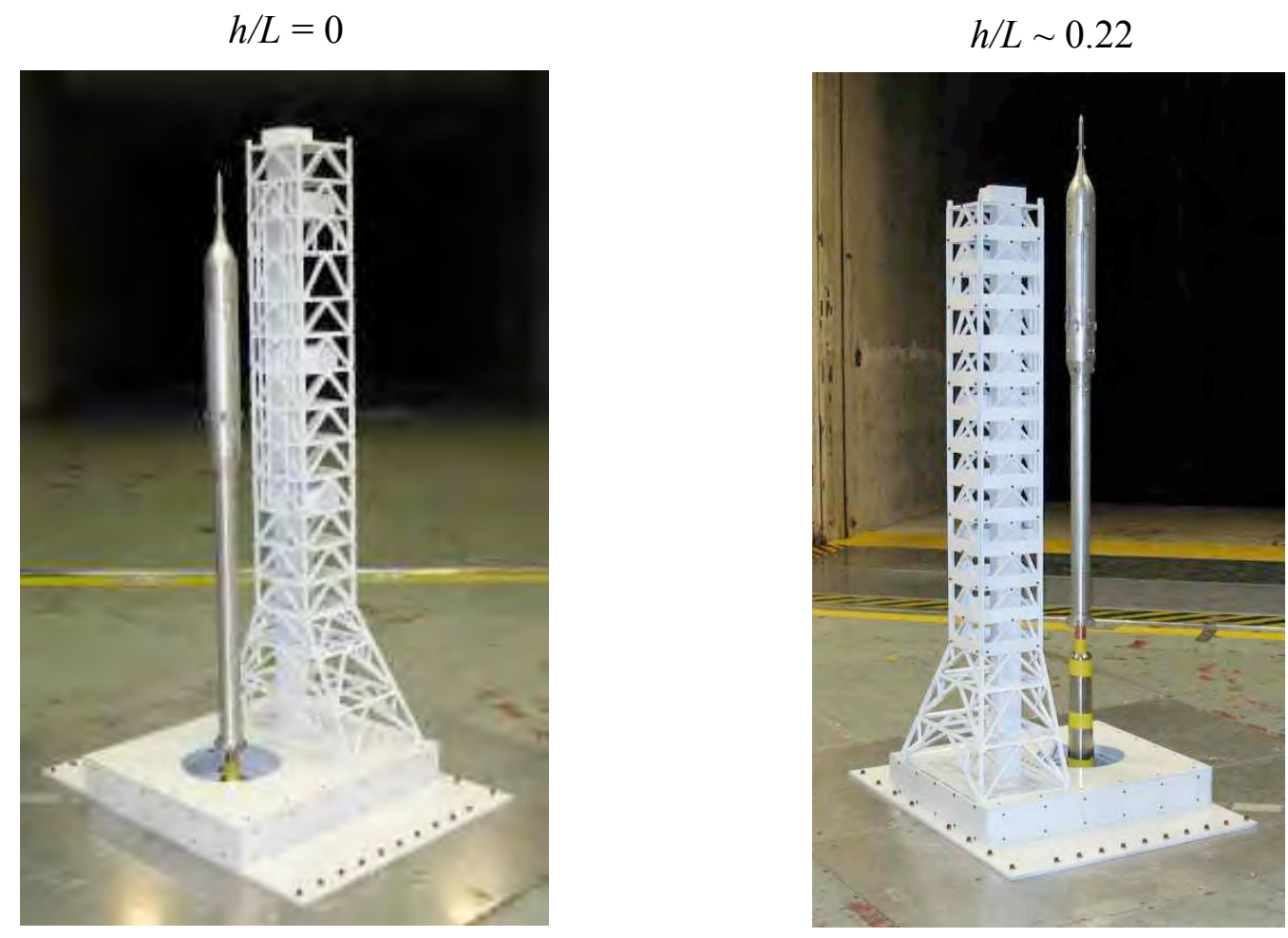

$h / L \sim 0.4$

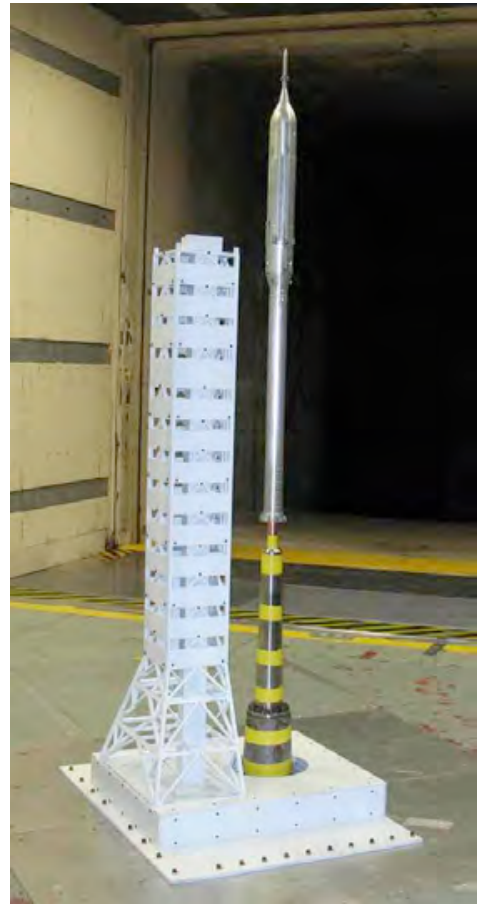

Figure 8. Photographs showing model installed in the liftoff mode. 
Baseline - No porosity plates

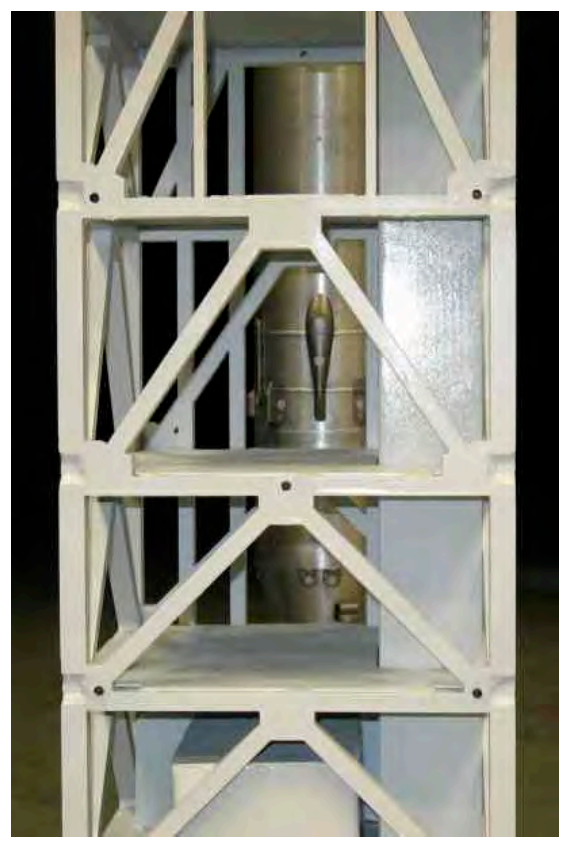

$1 / 3$ porosity plates

$2 / 3$ porosity plates
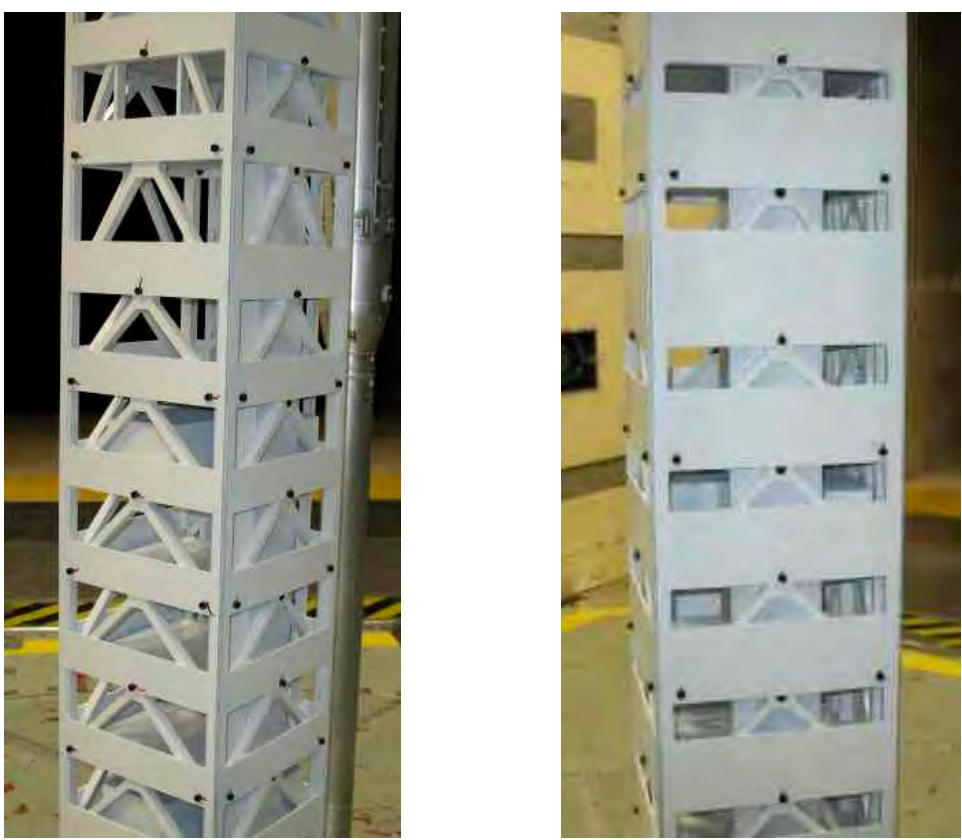

Figure 9. Photographs of tower with porosity plates. 

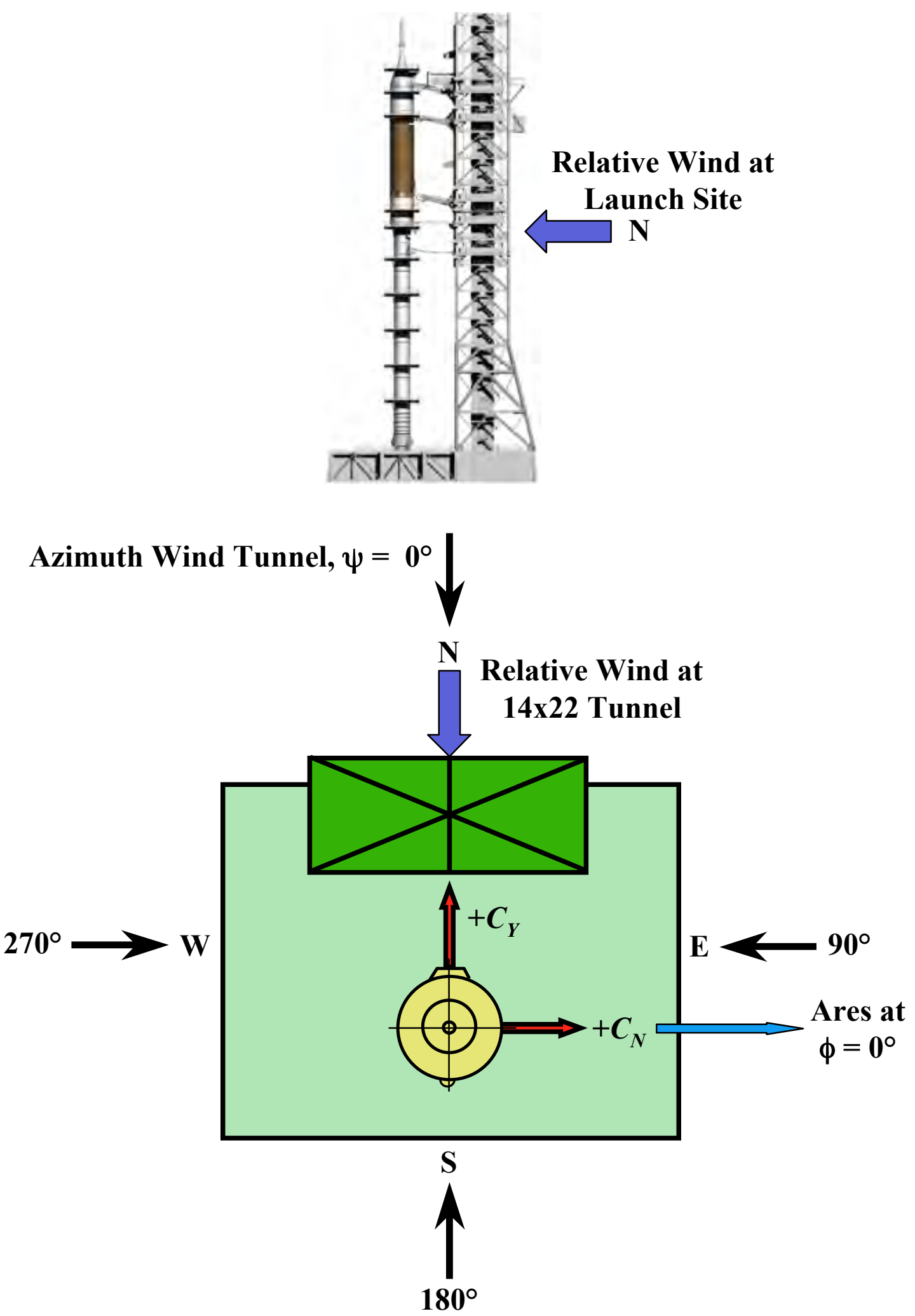

Figure 10. Sketch showing installation of Ares 1 with respect to launch tower. 


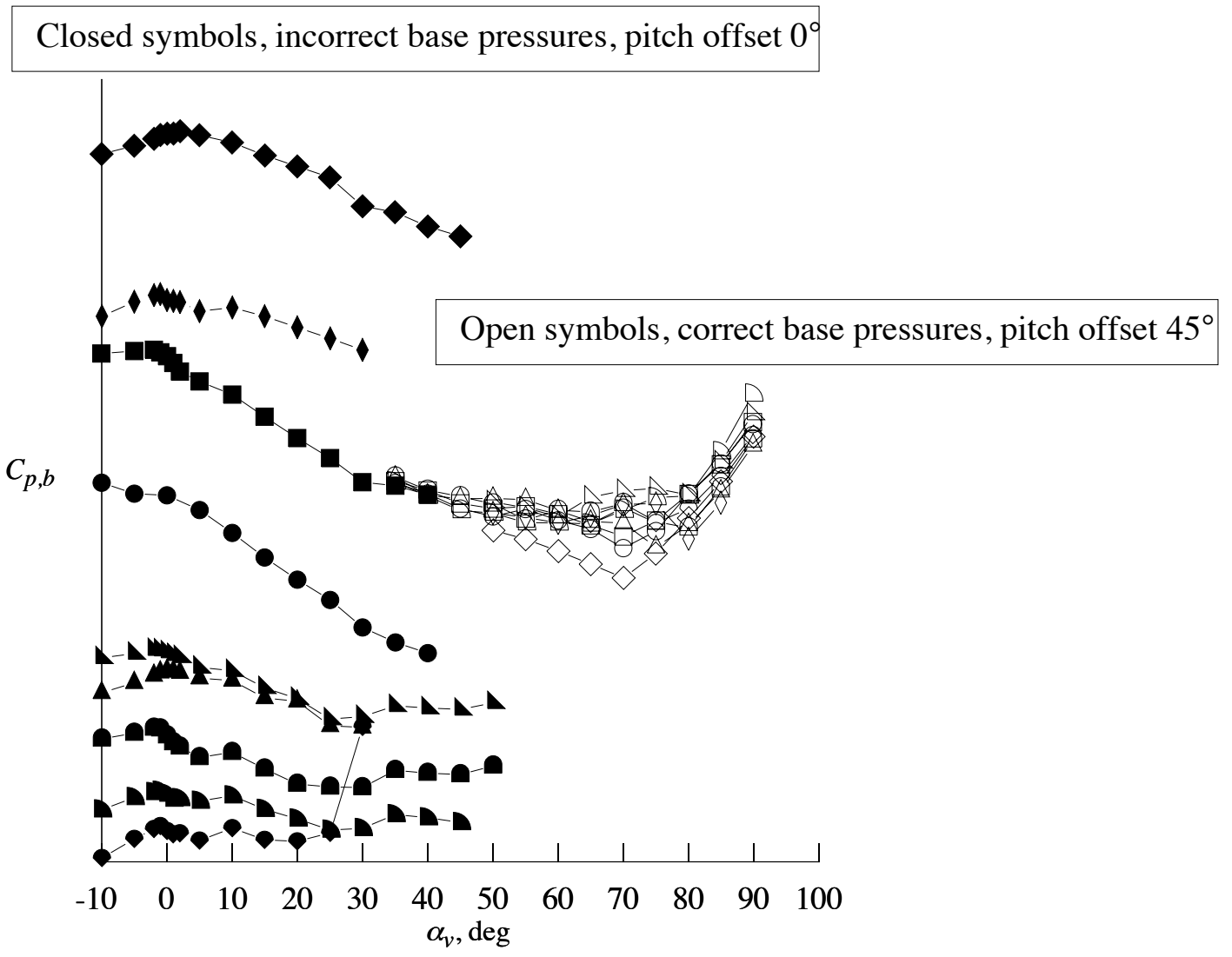

Figure 11. Some data runs with incorrect base pressure coefficients, transition mode, $q=40$ and $80 \mathrm{psf}, \phi=0^{\circ}$ to $90^{\circ}$.

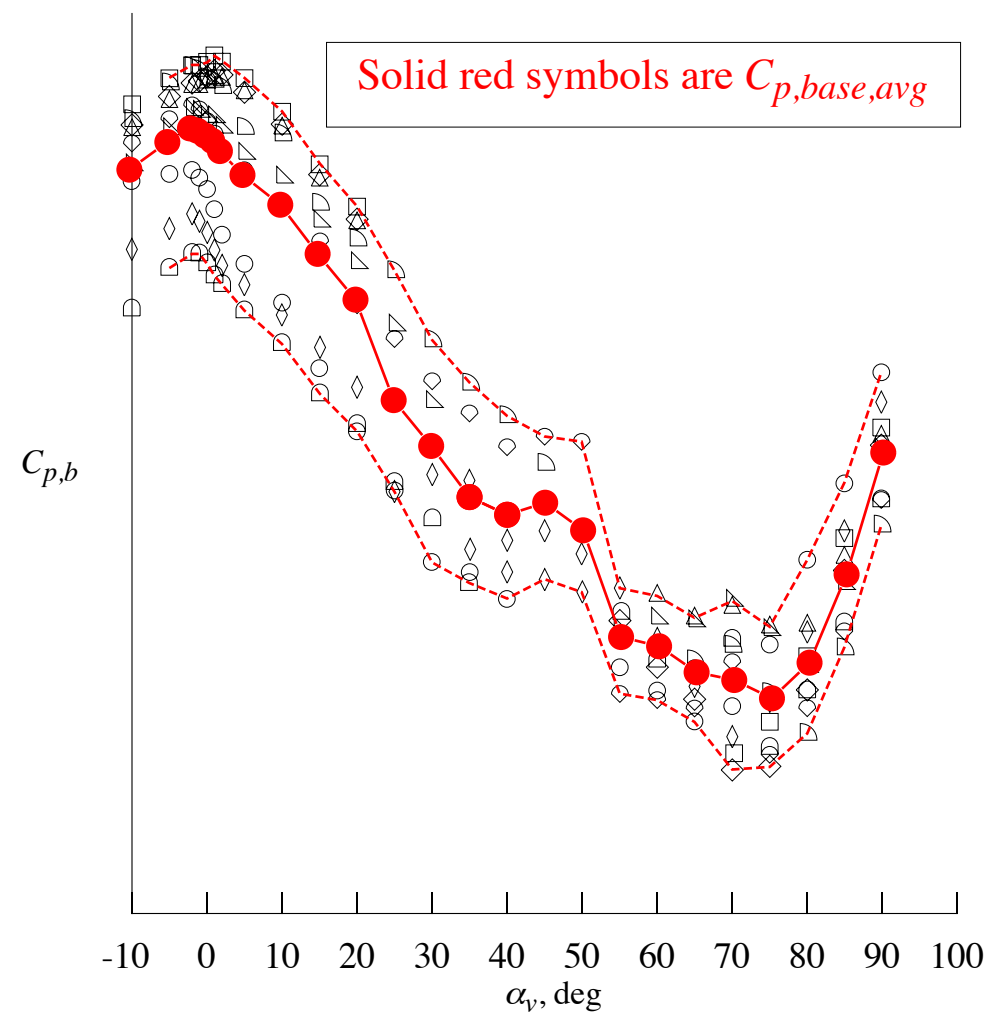

Figure 12. Symbols are data runs used to determine average base pressure coefficient. Maximum and minimun deviations are defined by dashed lines. 


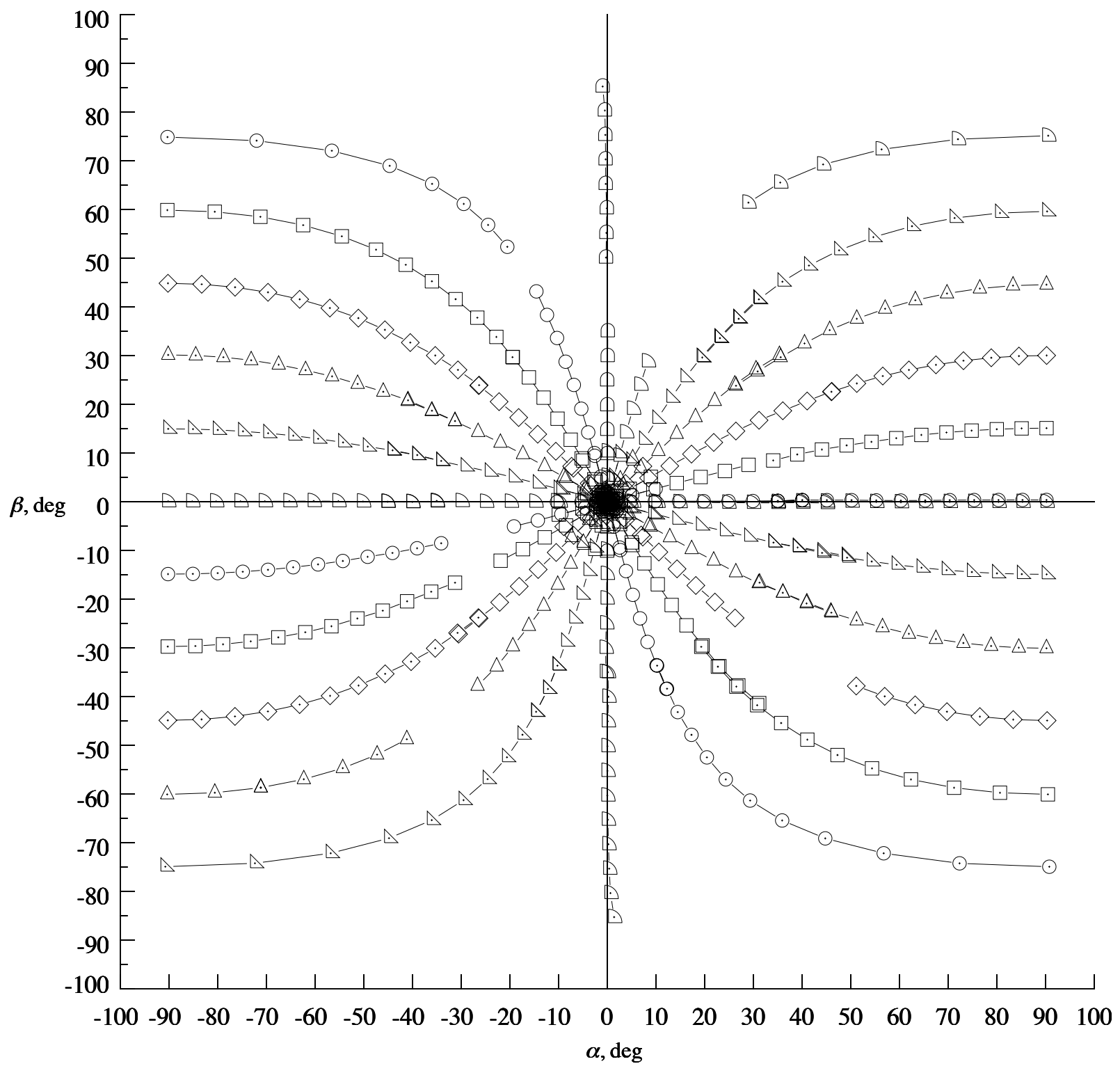

Figure 13. Variation of sideslip with angle of attack, body axis. 


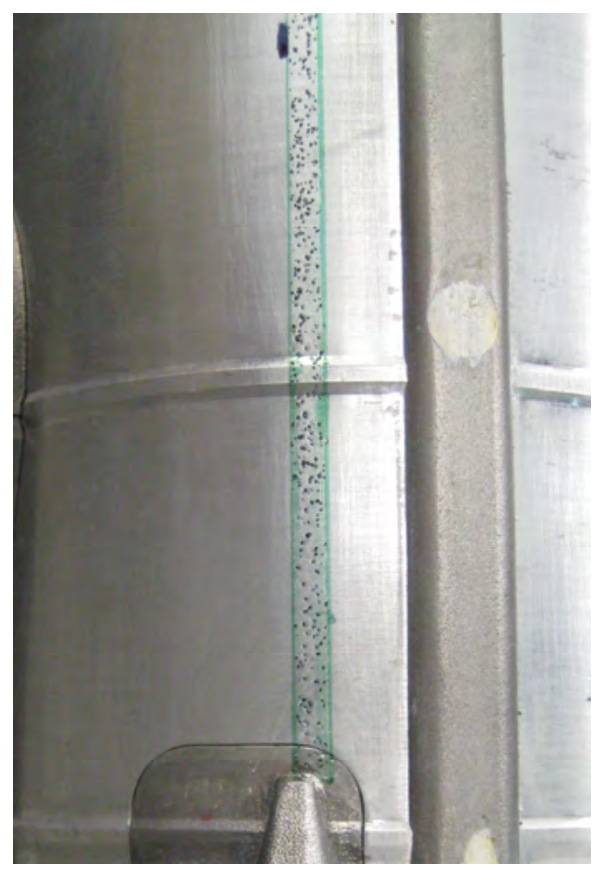

a. \#80 grit strip.

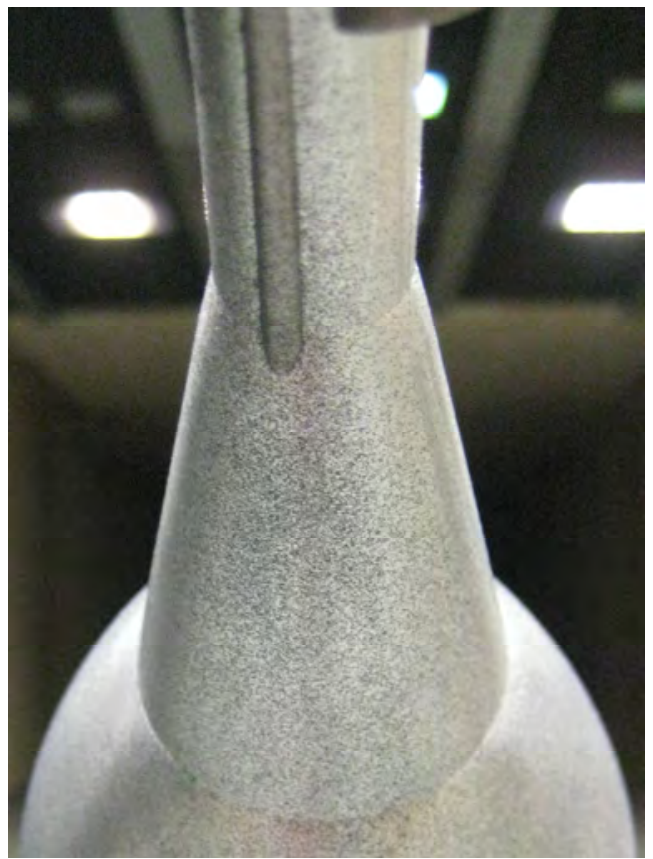

b. \#80 grit full, heavy.

Figure 14. Photographs of transition grit applications. 


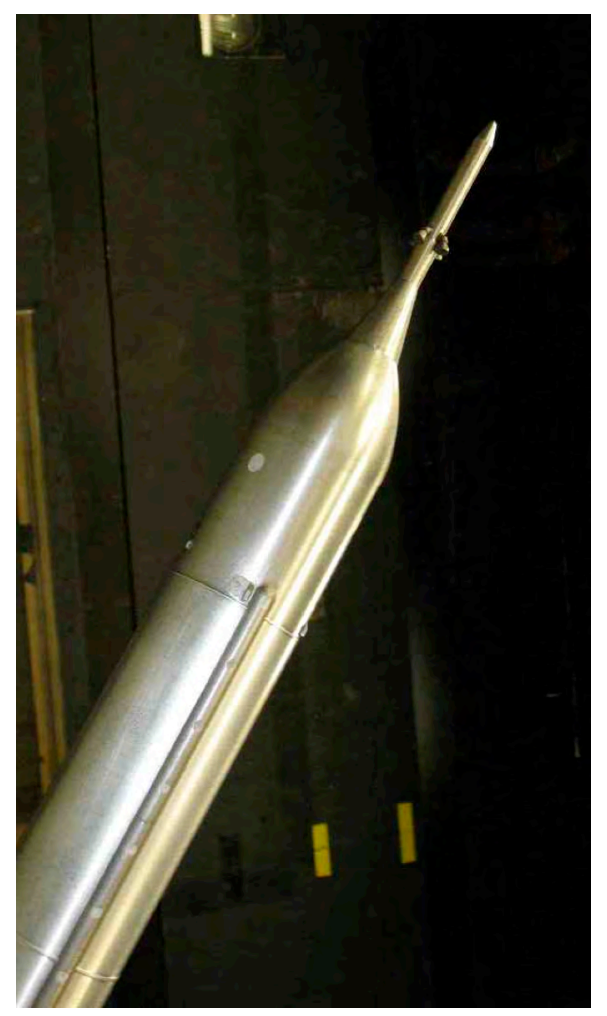

a. Transition free.

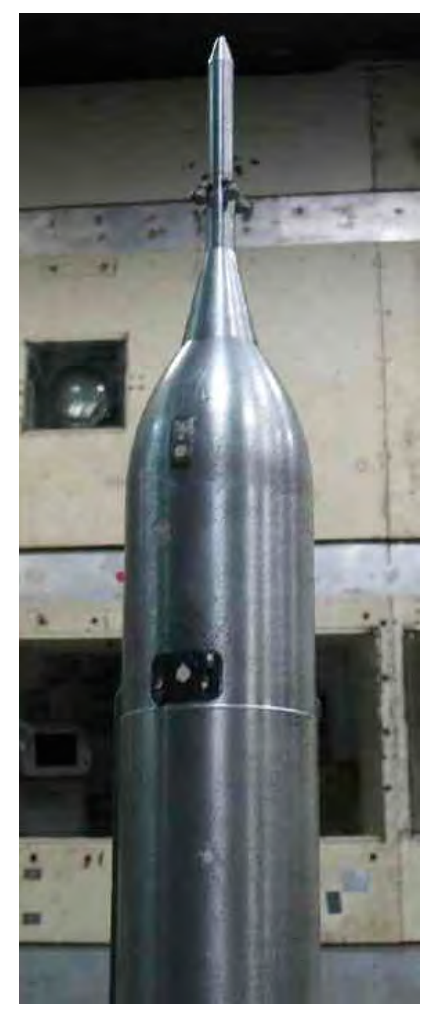

b. \#80 grit full.

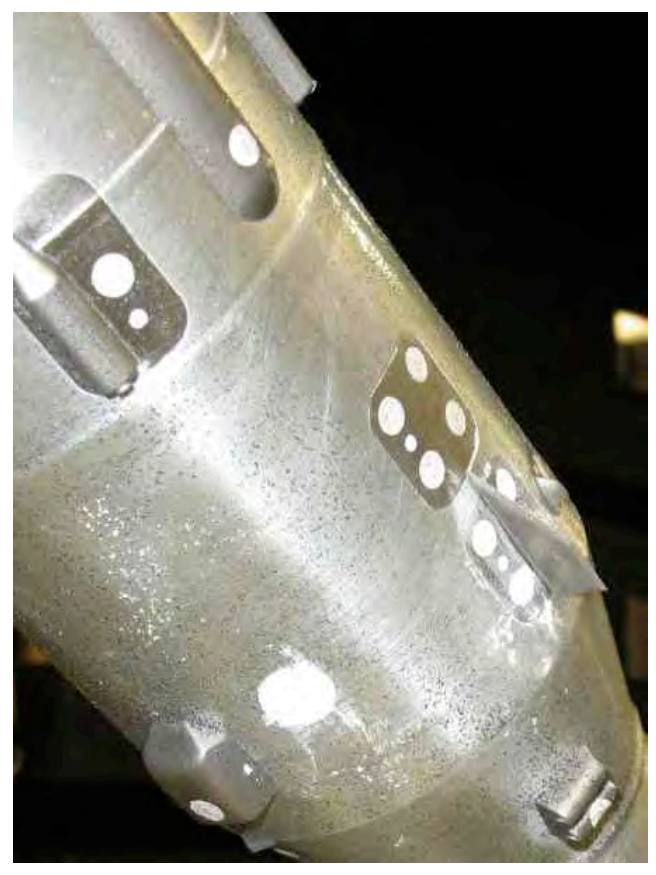

c. \#80 grit full.

Figure 15. Photographs of transition grit applications. 

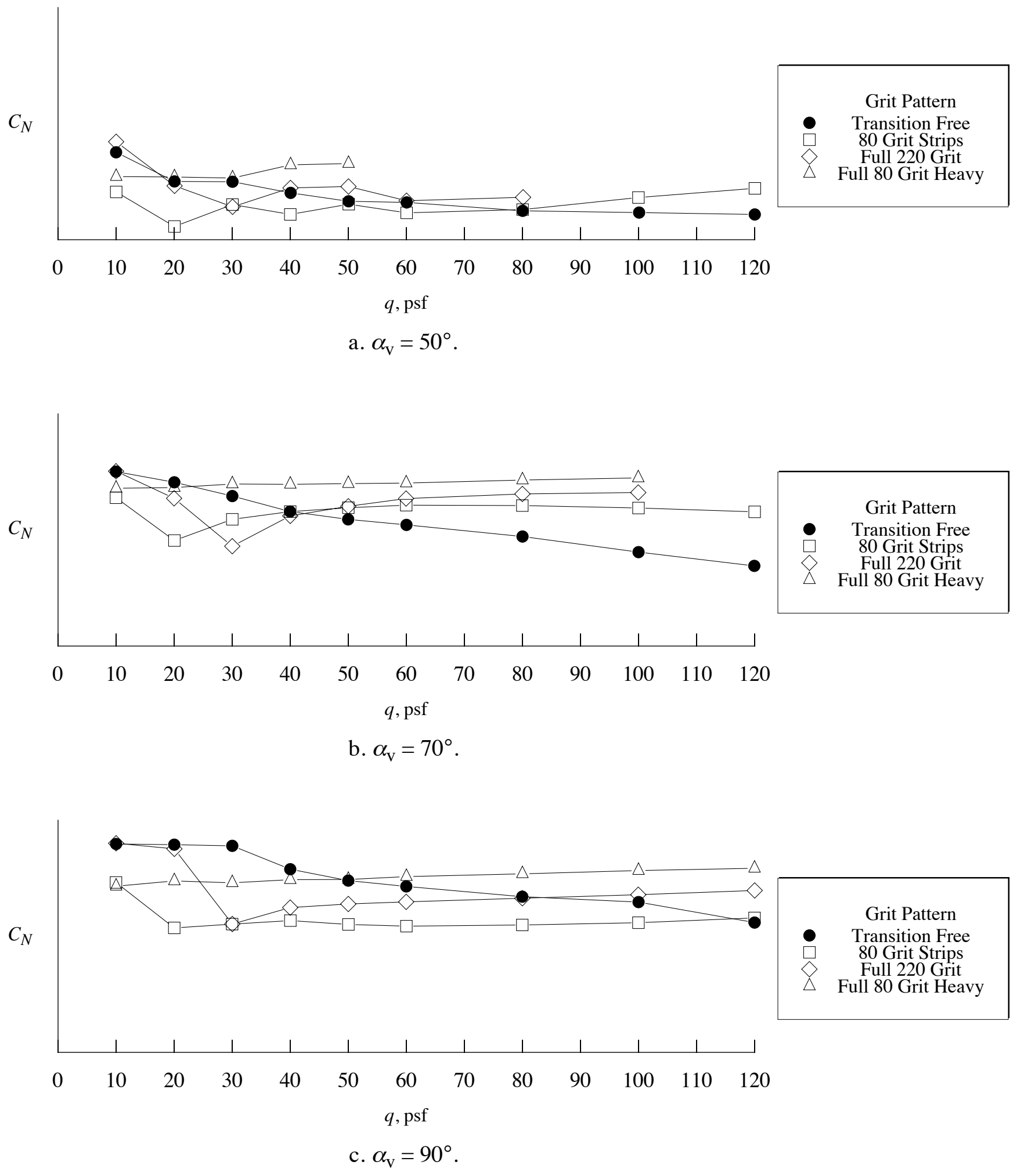

Figure 16. Effect of several transition schemes on Ares I normal force coefficient, $\phi=0^{\circ}$. 

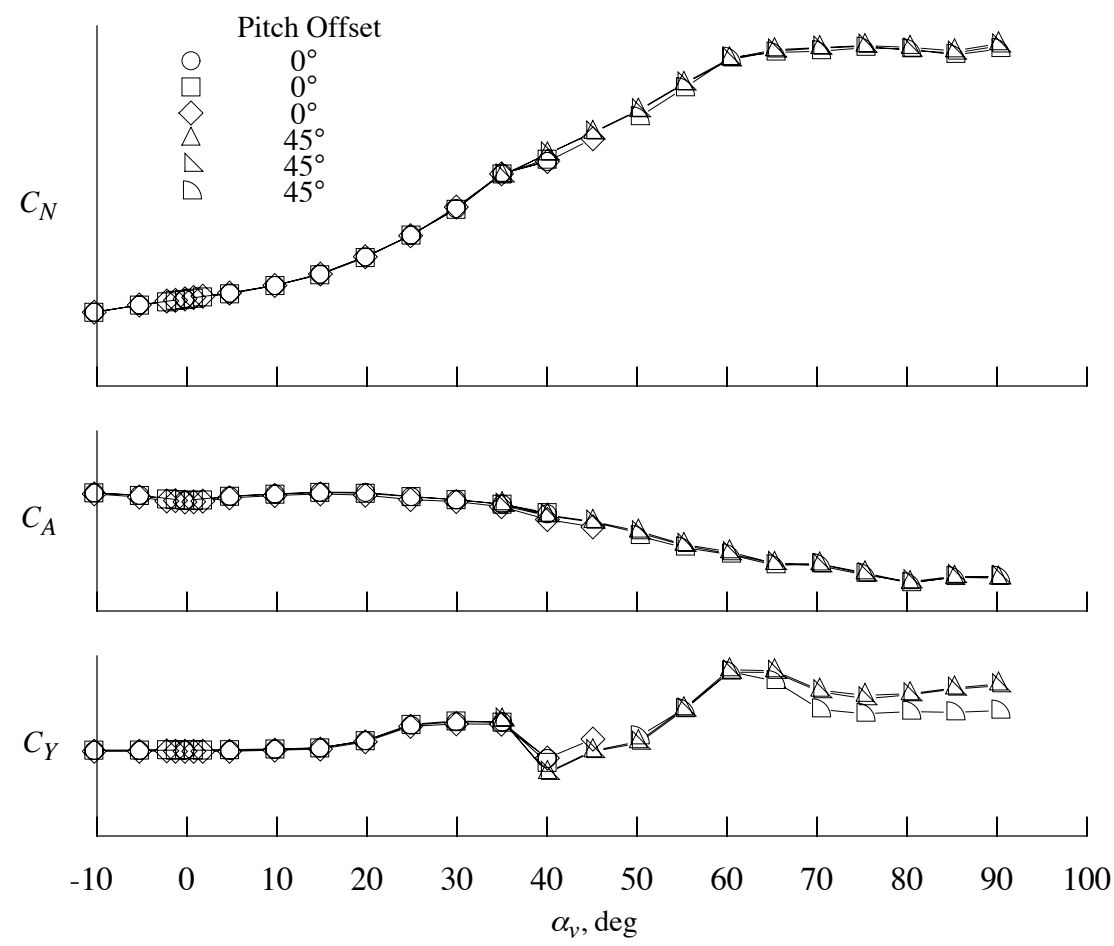

Figure 17. Example of excellent repeatability of forces from pitch sweeps, transition mode, $q=40 \mathrm{psf}, \phi=0^{\circ}$.
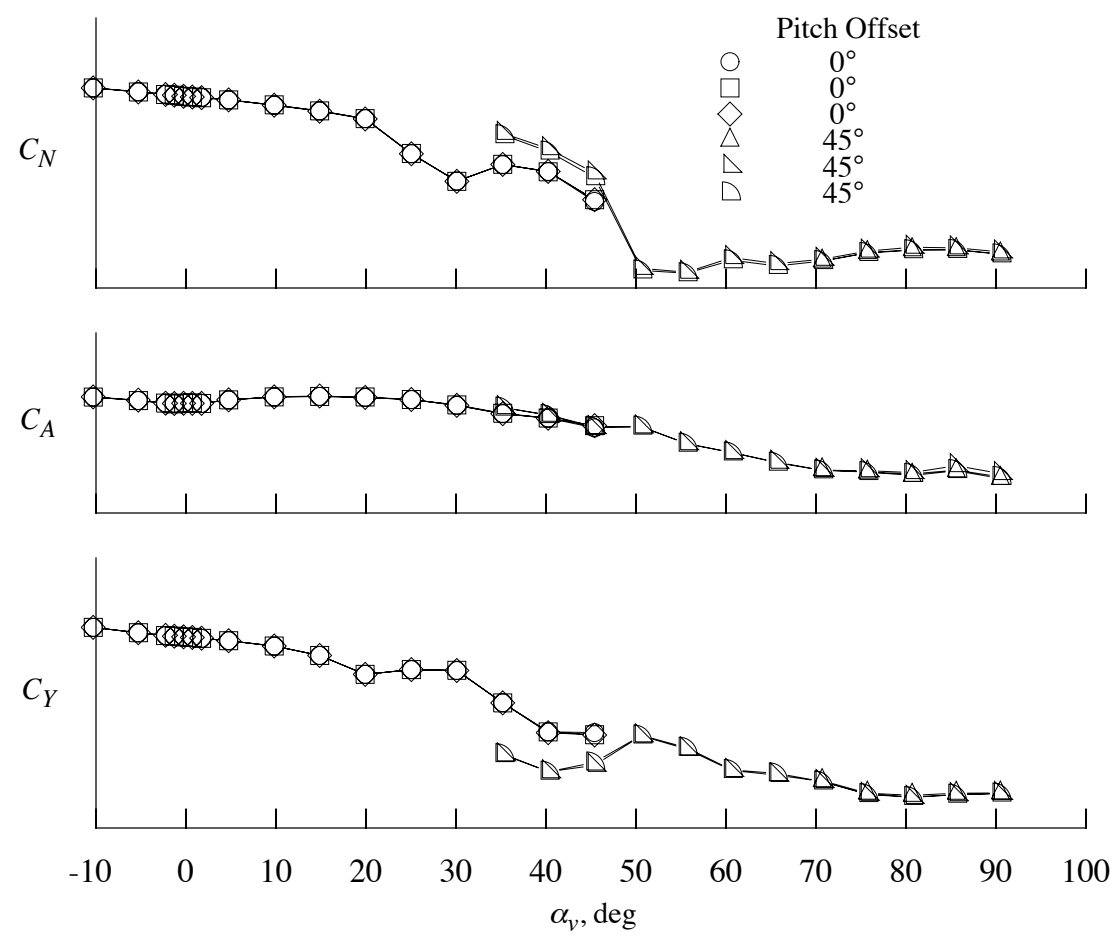

Figure 18. Example of not so excellent repeatability of forces from pitch sweeps, transition mode, $q=80 \mathrm{psf}, \phi=135^{\circ}$. 

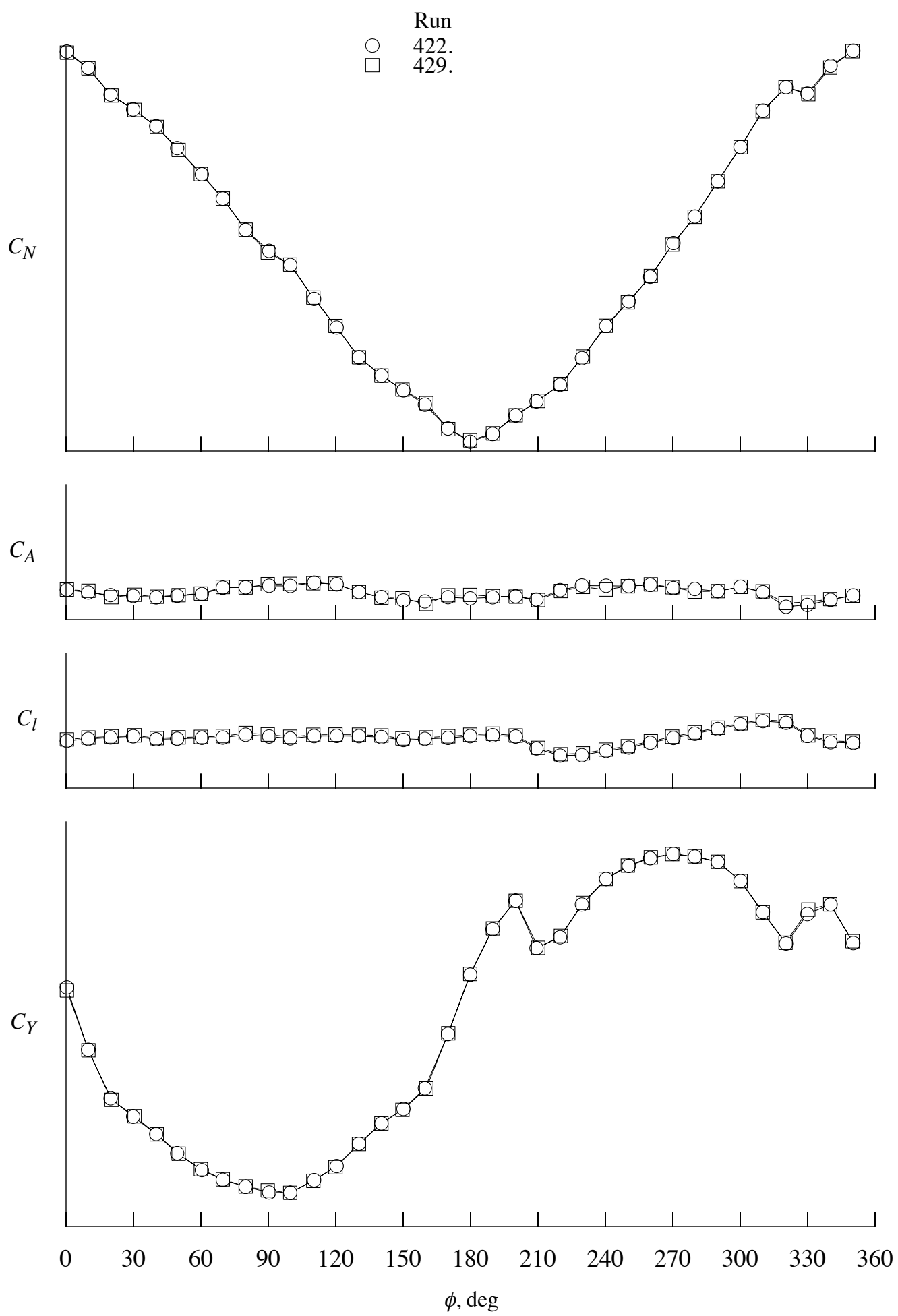

Figure 19. Example of excellent repeatability of forces from roll sweeps, transition mode, $q=80 \mathrm{psf}, \alpha_{v}=90^{\circ}$. 

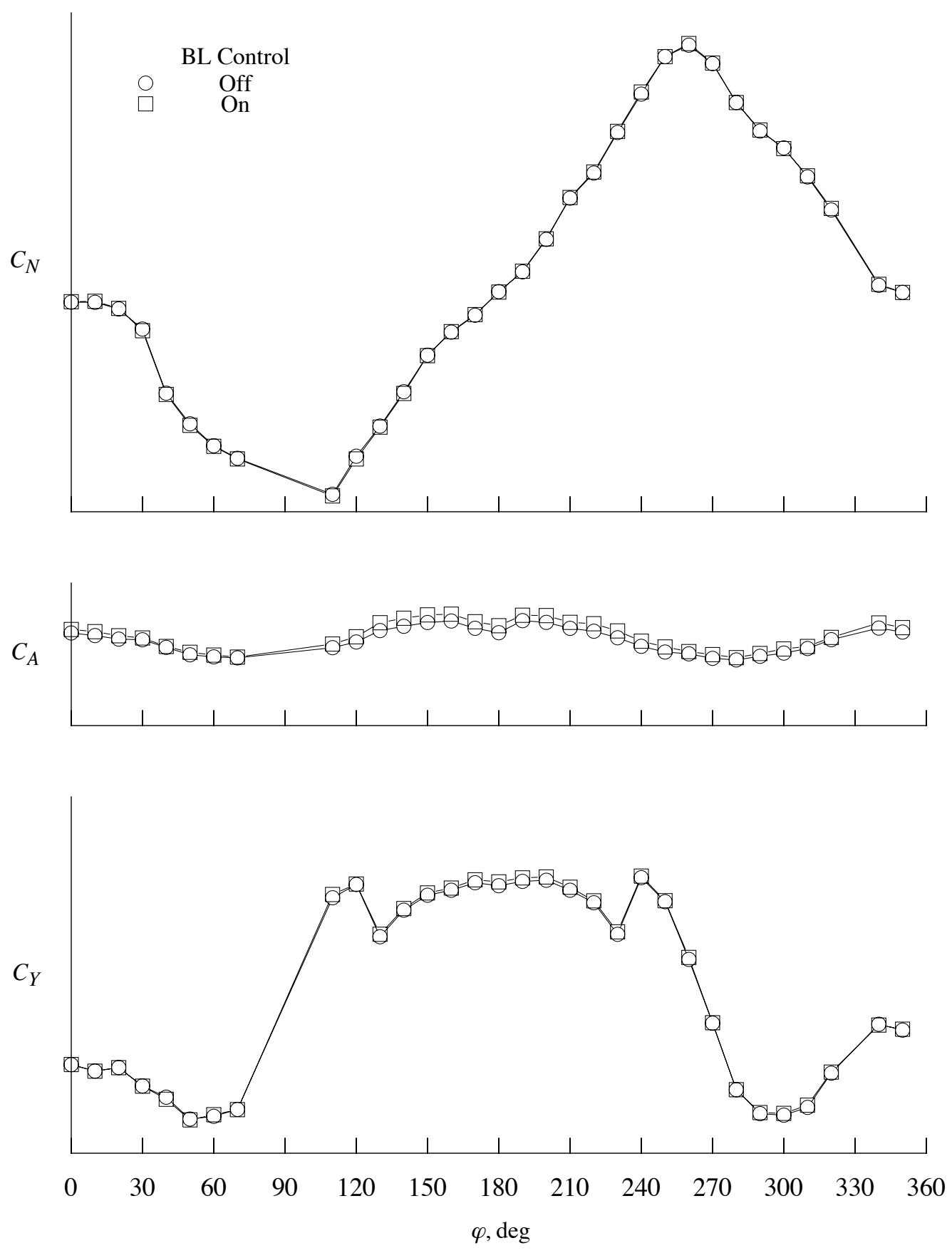

Figure 20. Example of excellent repeatability of forces from azimuth sweeps, liftoff mode, baseline tower, $q=40 \mathrm{psf}, x / L=0$. 

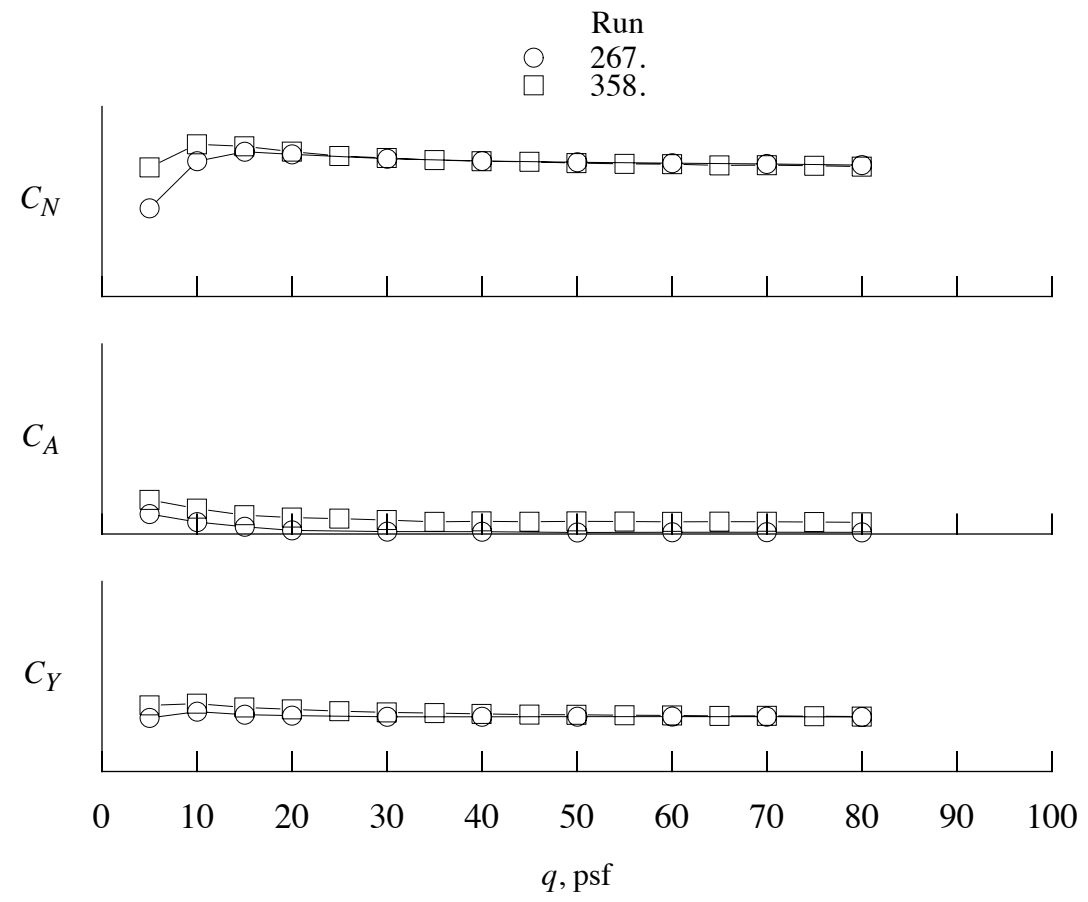

Figure 21. Example of excellent repeatability of forces from $q$ sweeps, liftoff mode, baseline tower, $x / L=0, \varphi=45^{\circ}$.
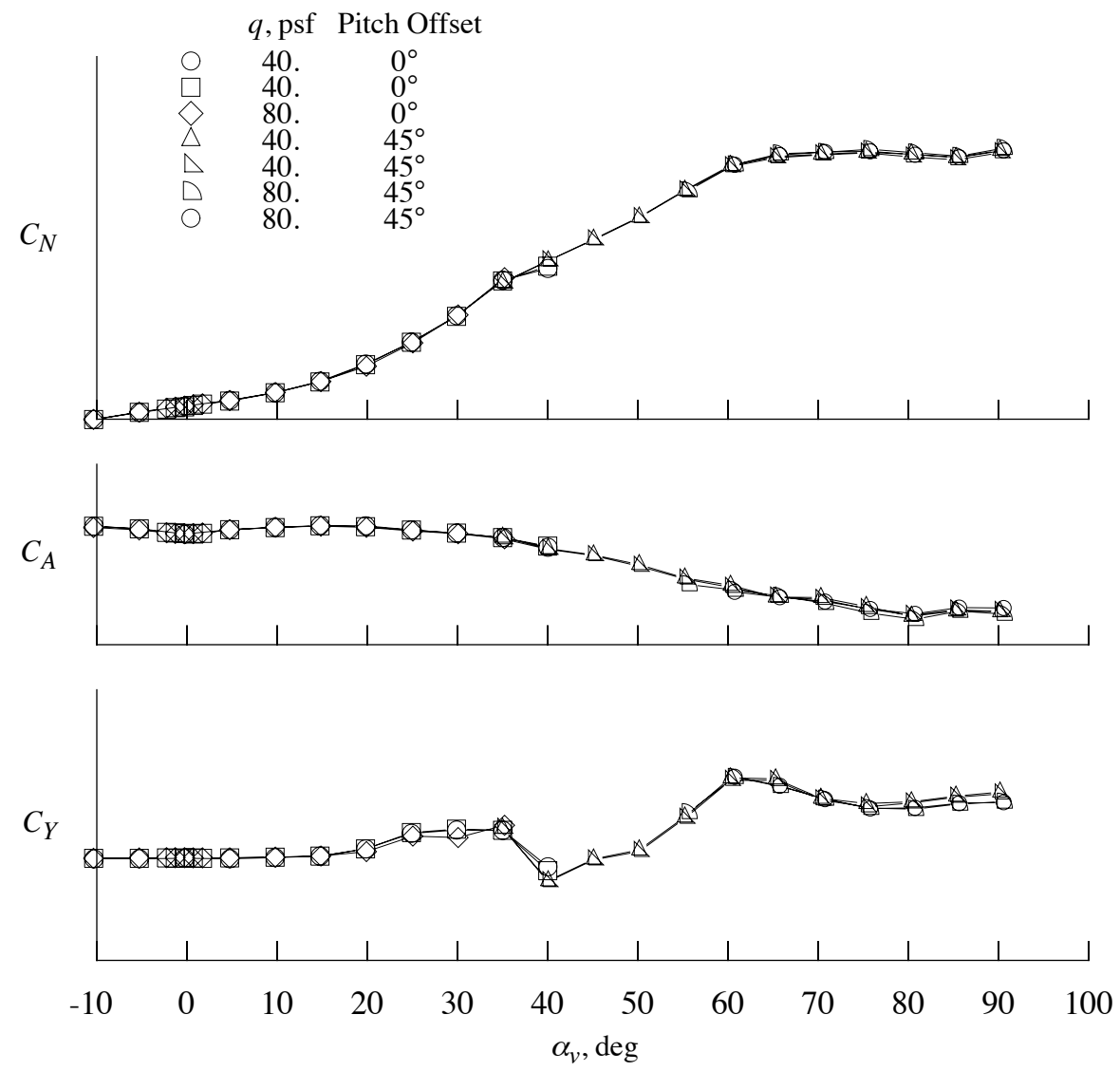

Figure 22. Example of excellent corellation of forces at two values of $q$, transition mode, $\phi=0^{\circ}$. 


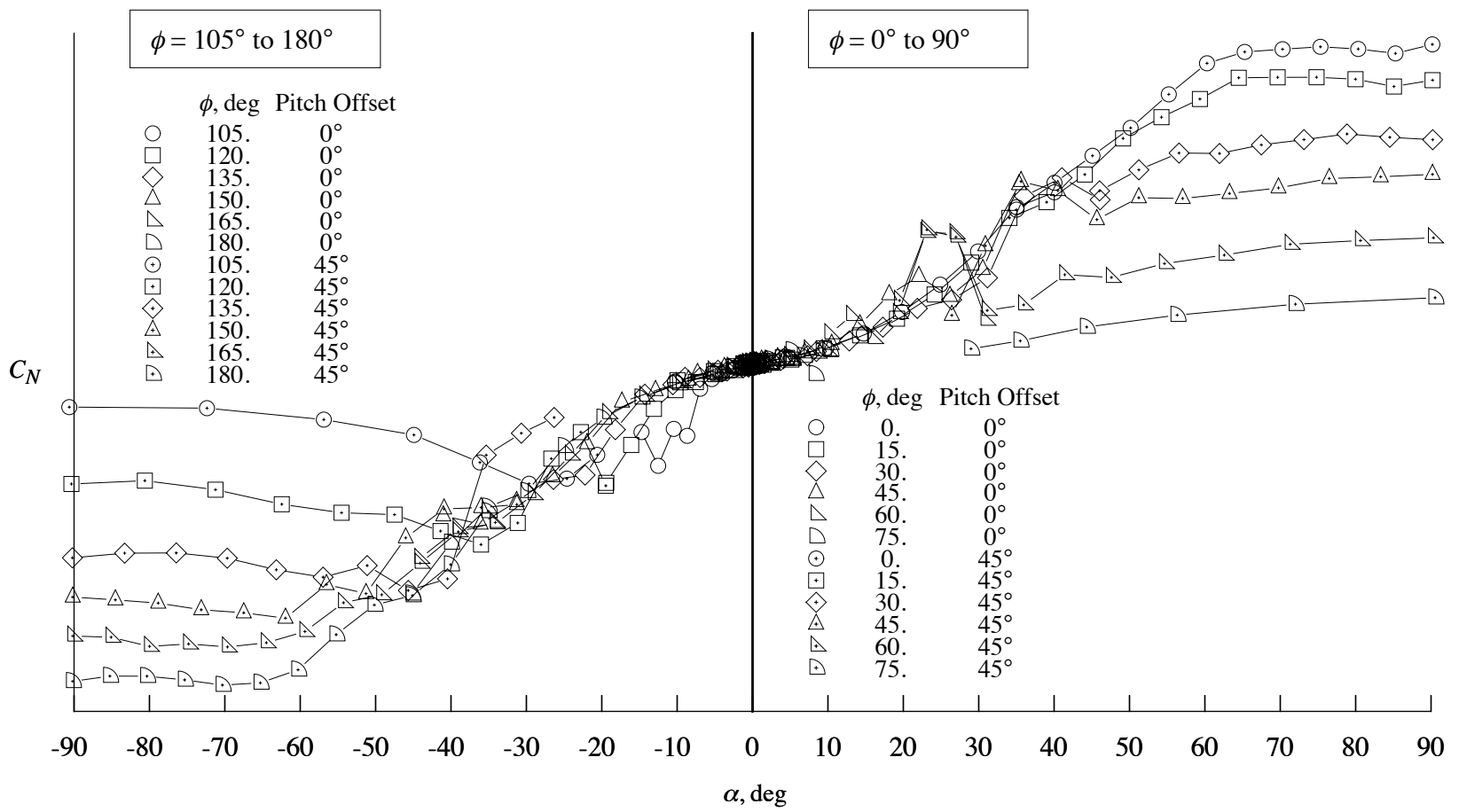

Figure 23. Variation of Ares I normal force coefficient with angle of attack,transition mode, $q=40 \mathrm{psf}$.

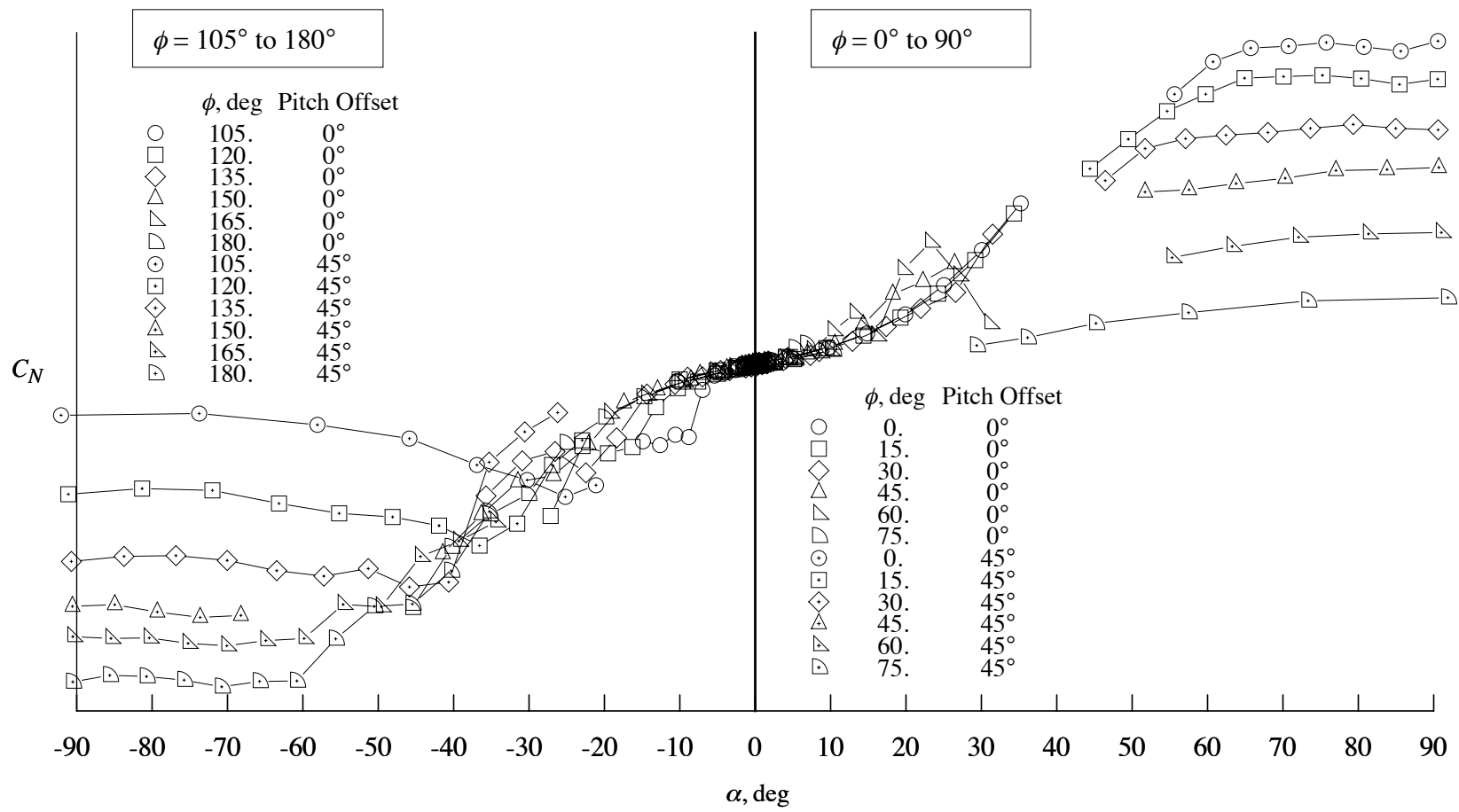

Figure 24. Variation of Ares I normal force coefficient with angle of attack,transition mode, $q=80 \mathrm{psf}$. 


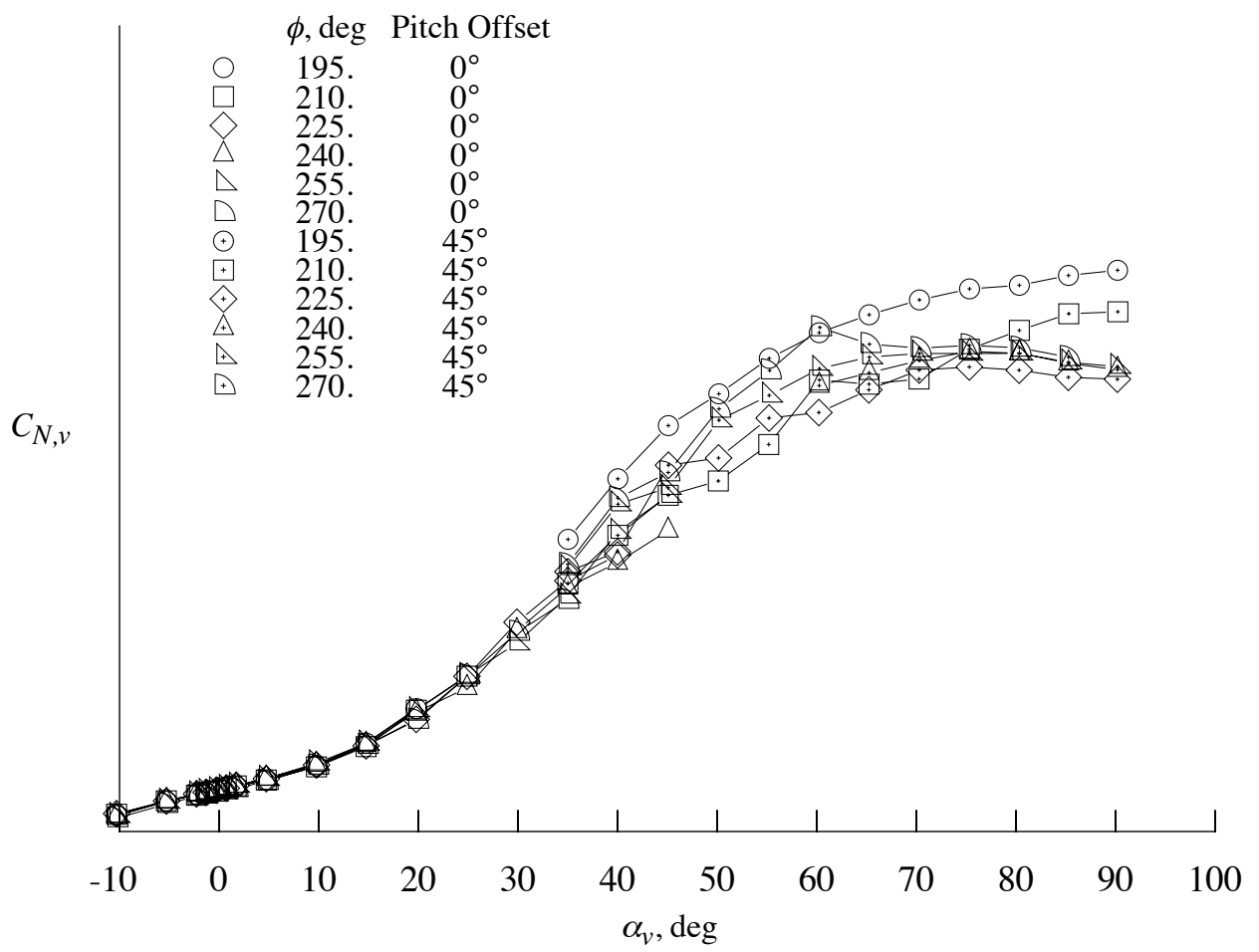

Figure 25. Typical variation of vertical axis normal force coefficient, $q=40 \mathrm{psf}$.

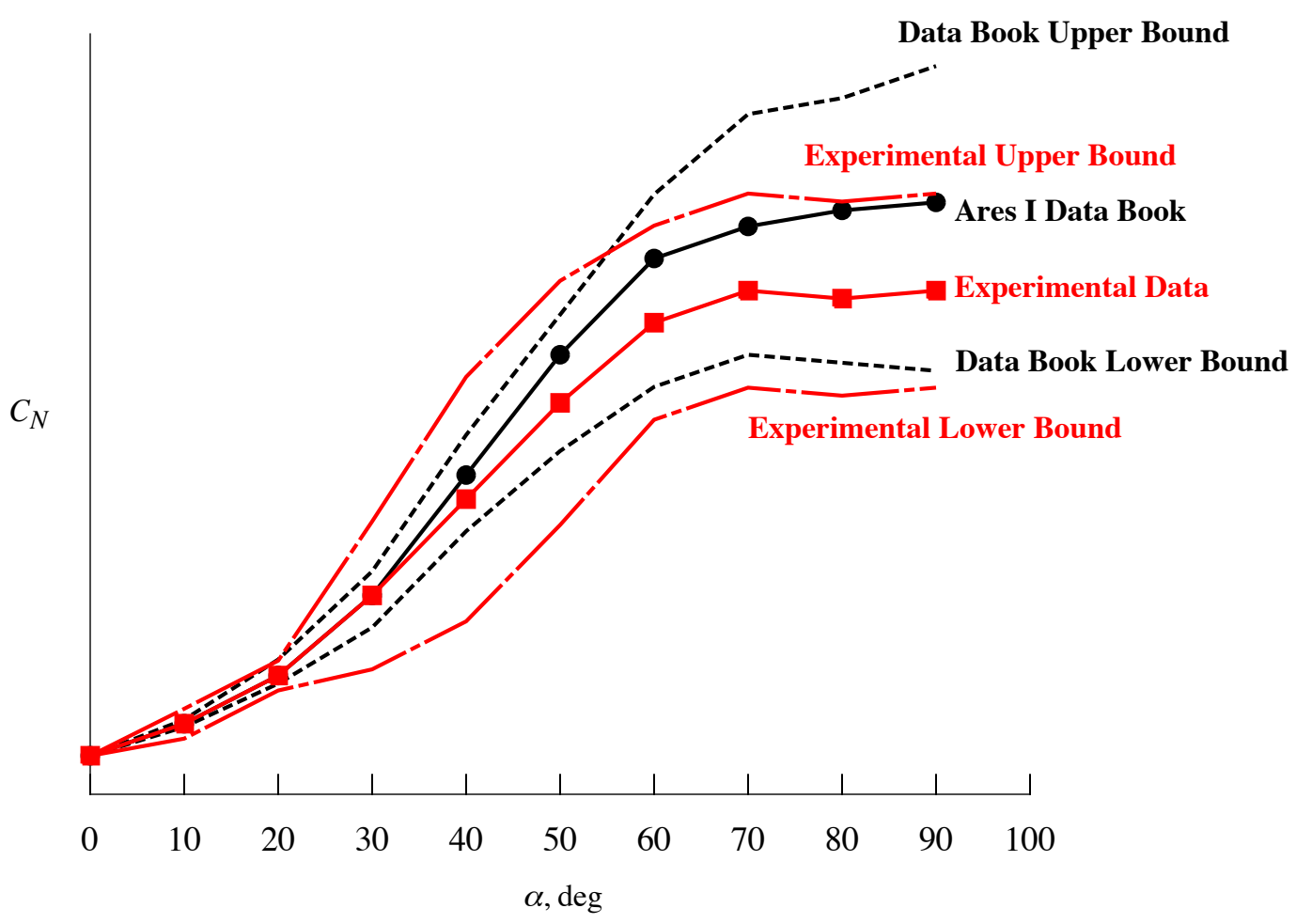

Figure 26. Comparison of Data Book $C_{N}$ to experimental $C_{N}$.

Symbols do not denote data points. 


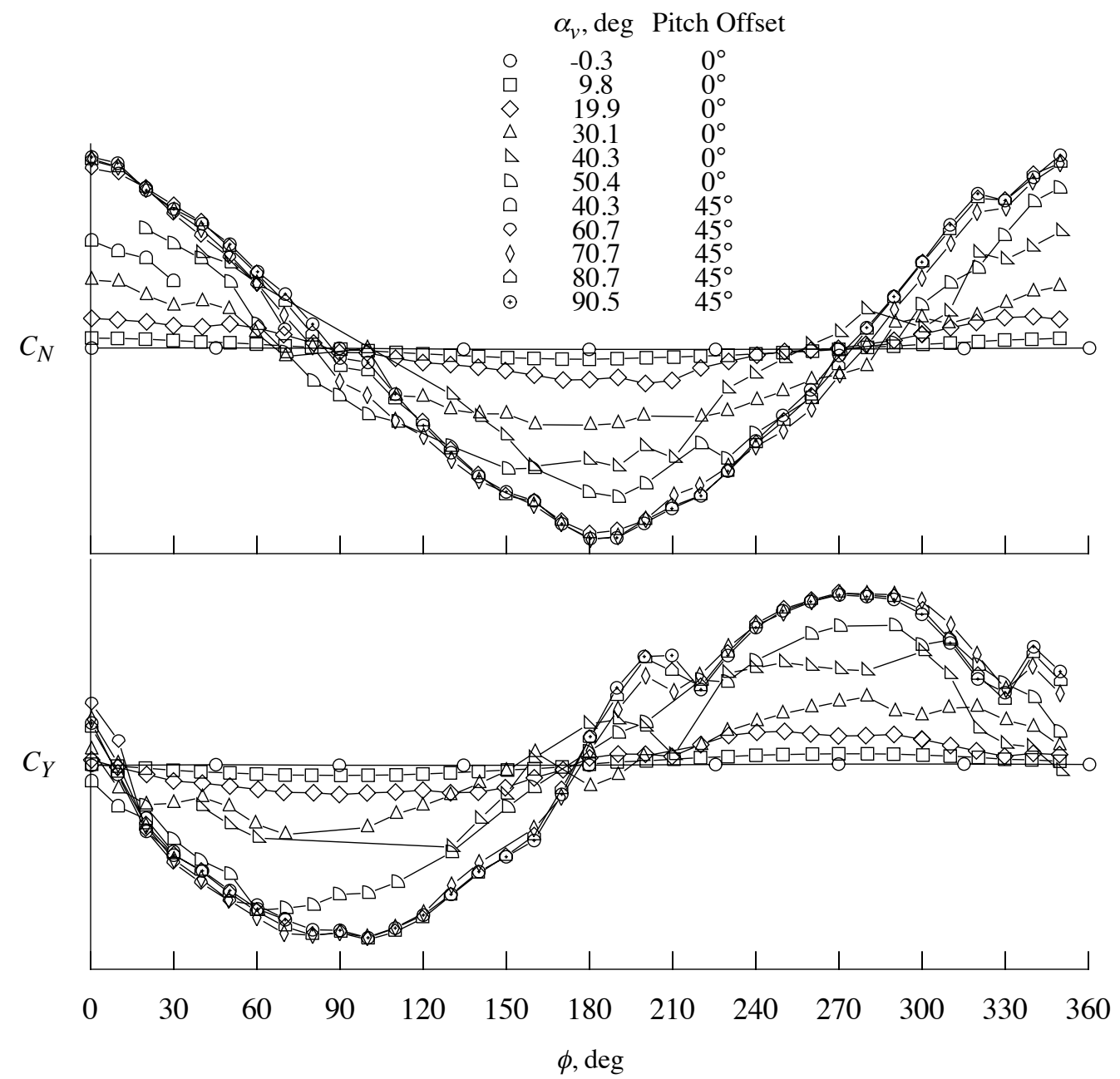

Figure 27. Variation of $C_{N}$ and $C_{Y}$ with roll angle, transition mode, $q=80$ psf.

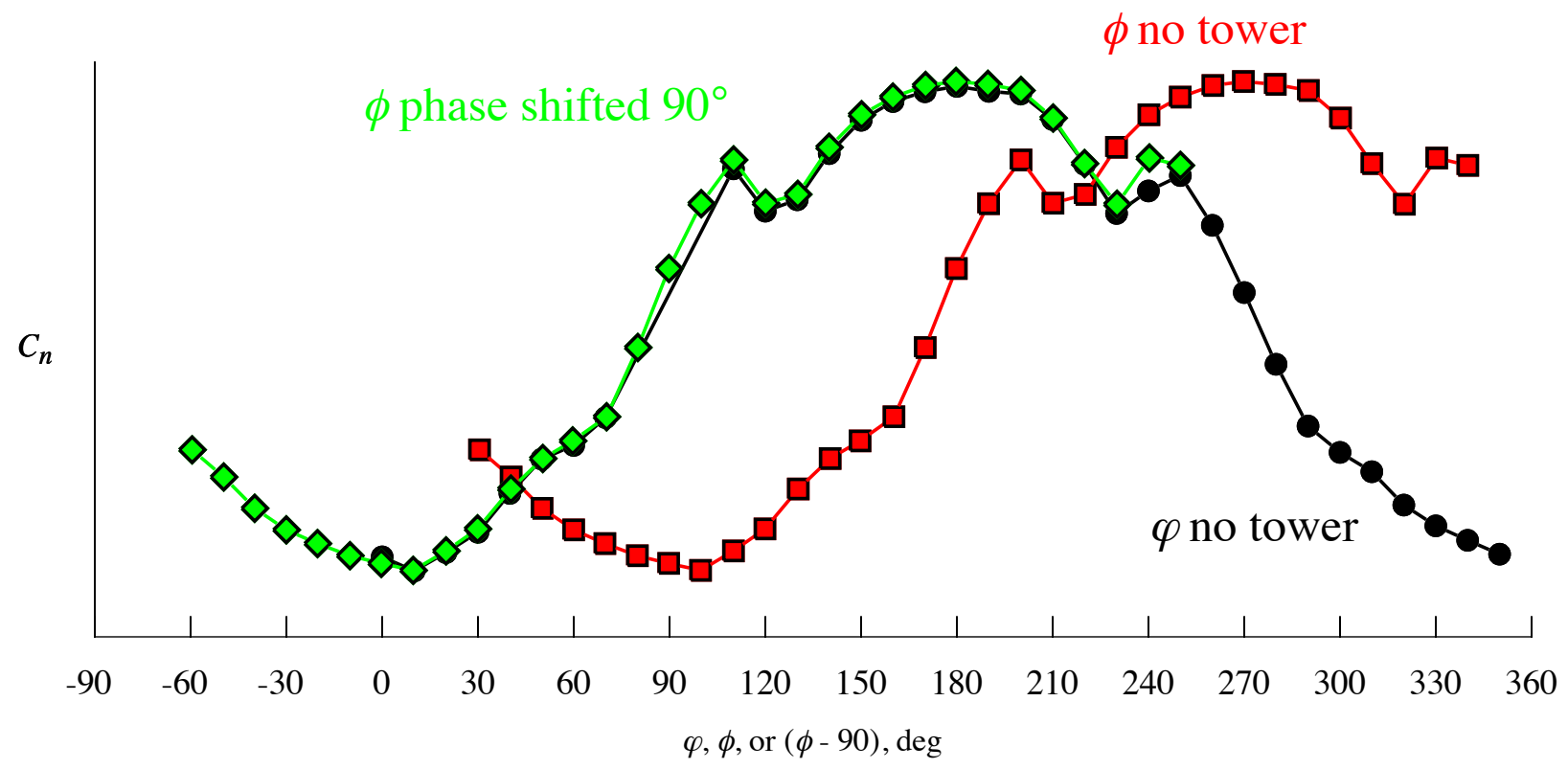

Figure 28. Comparison of yawing moments to phase shifted roll. 


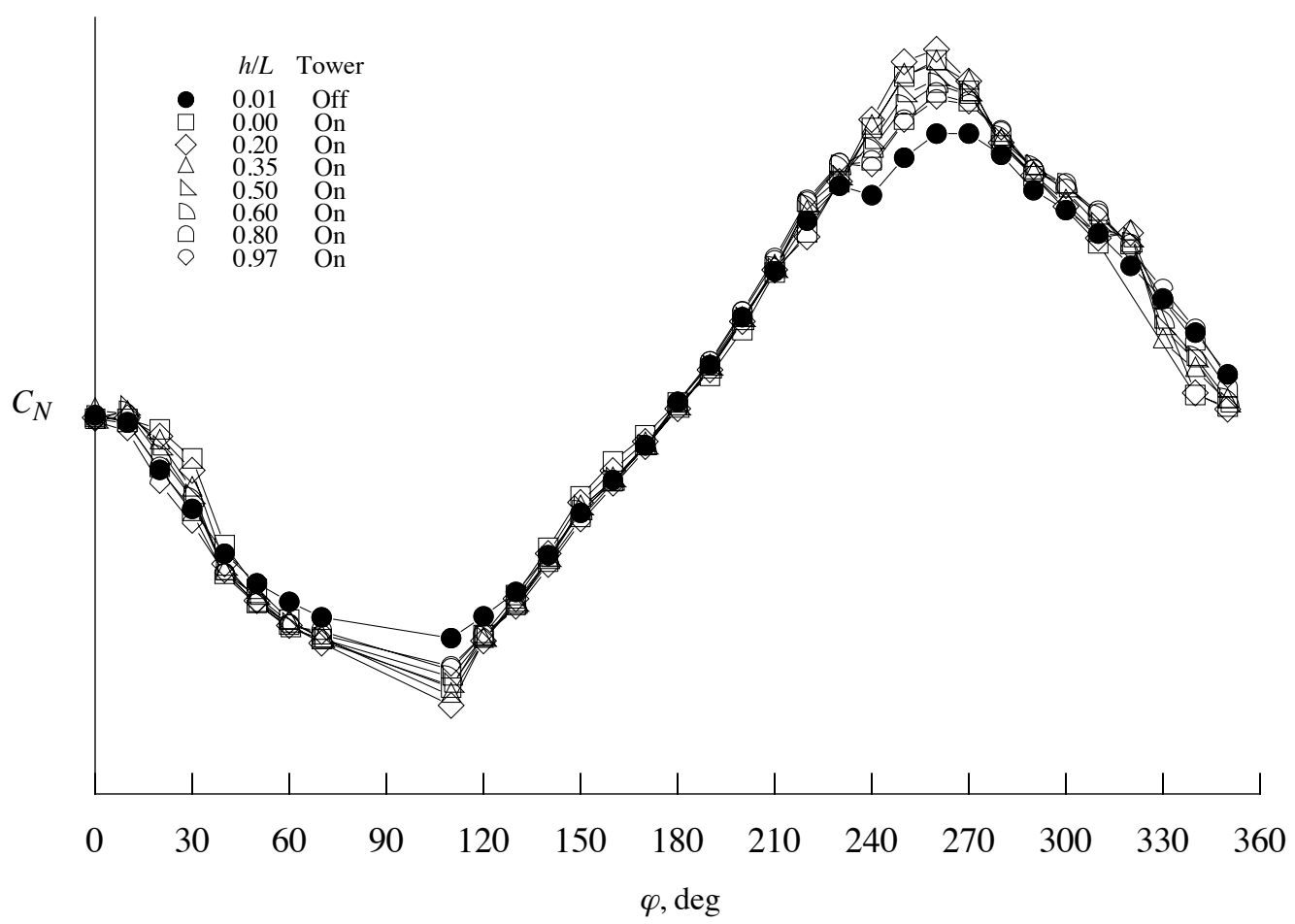

a. Normal force coefficient

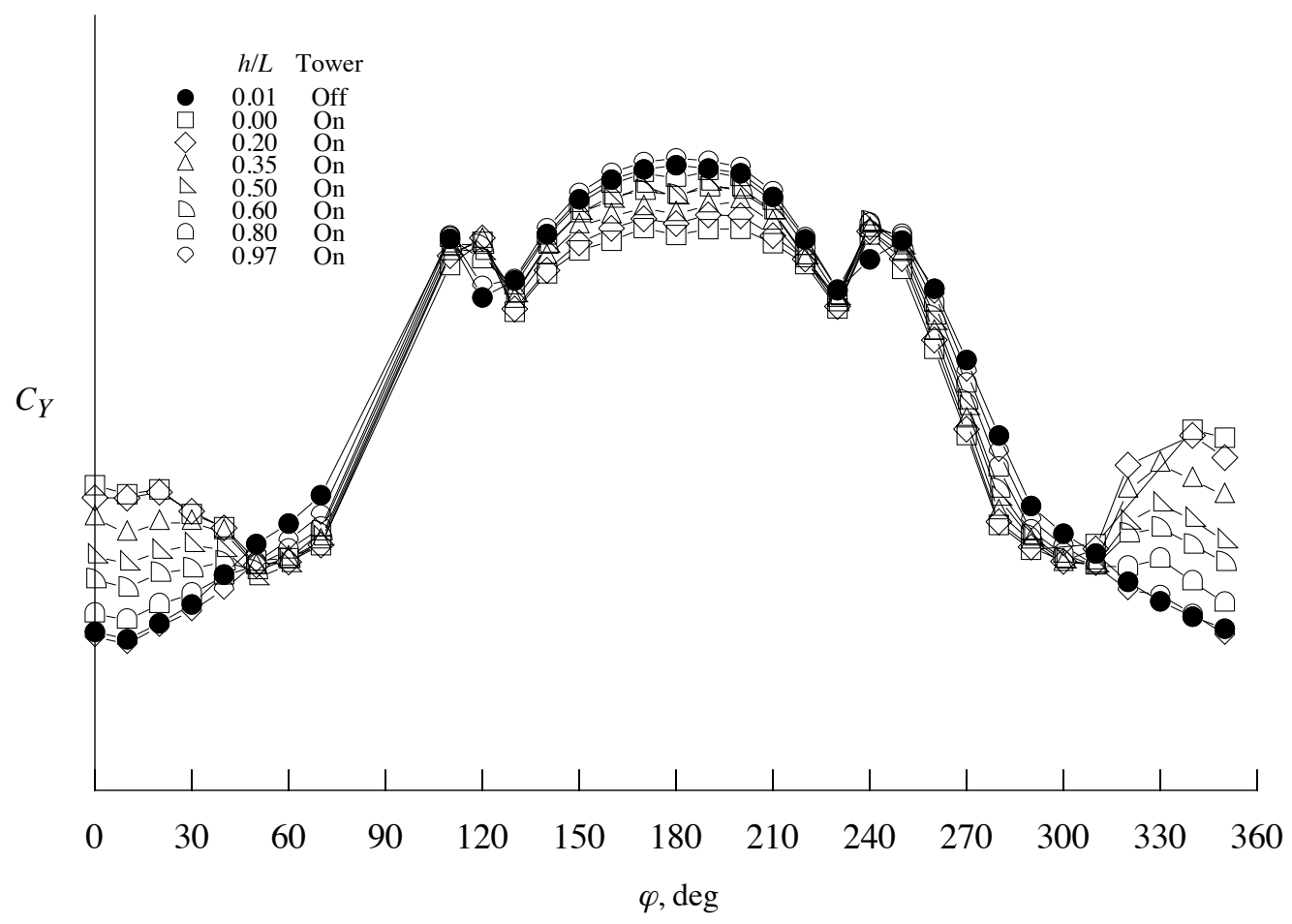

b. Side force coefficient

Figure 29. Effect of Ares I height above launch pad on $C_{N}$ and $C_{Y}$,liftoff mode, $q=80 \mathrm{psf}$. 


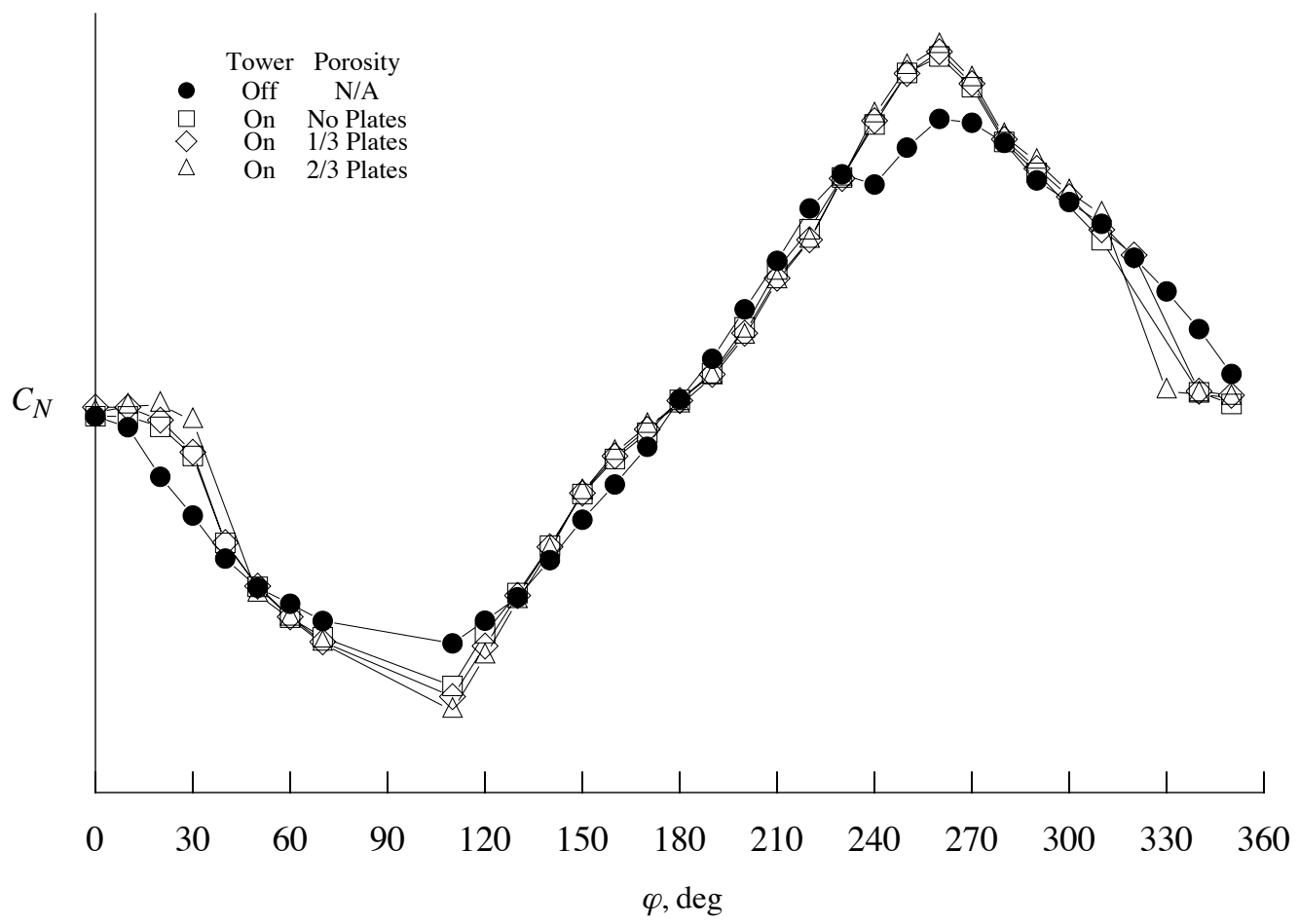

a. Normal force coefficient

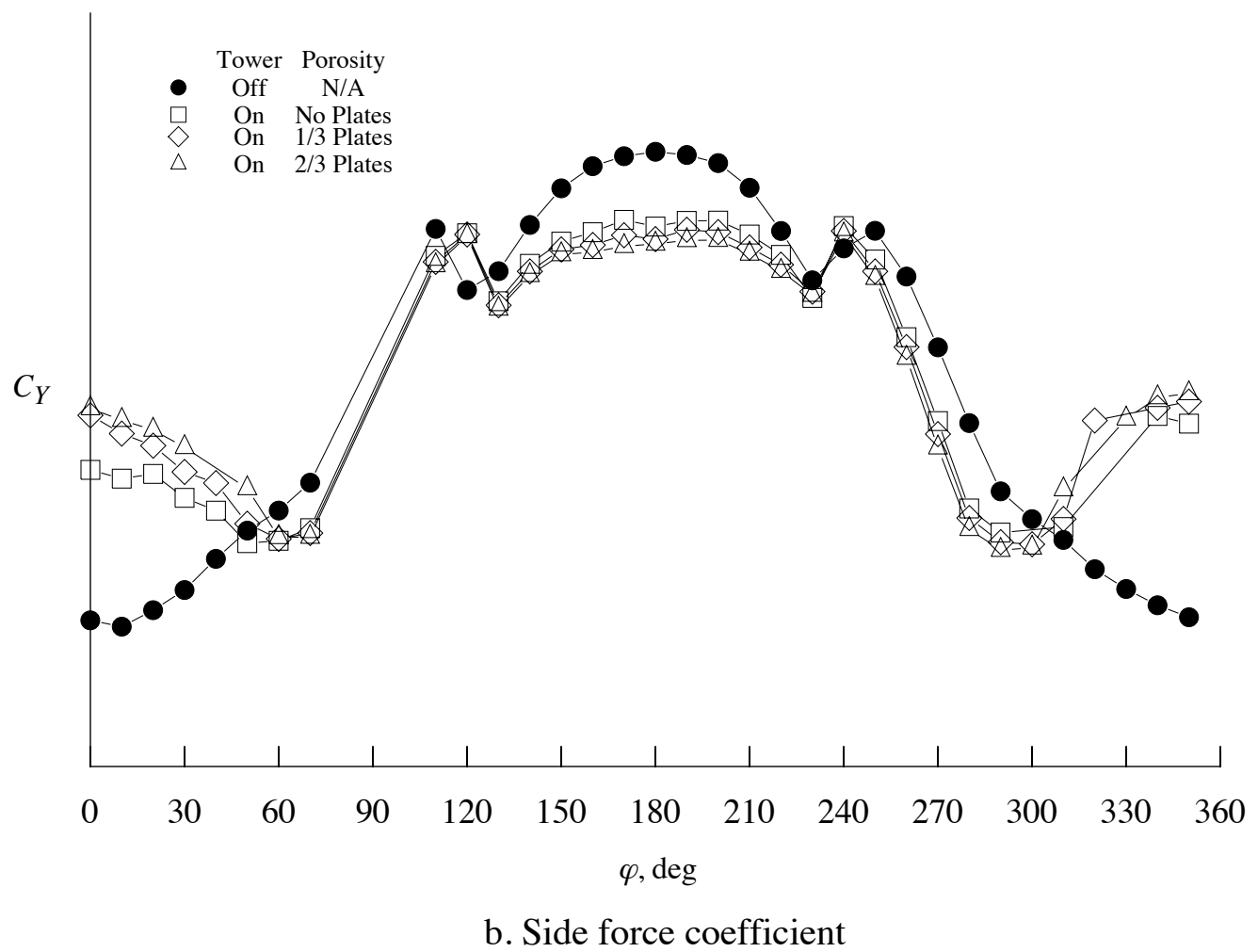

Figure 30. Effect of launch tower porosity Ares I $C_{N}$ and $C_{Y}, h / L=0.0, q=80 \mathrm{psf}$. 


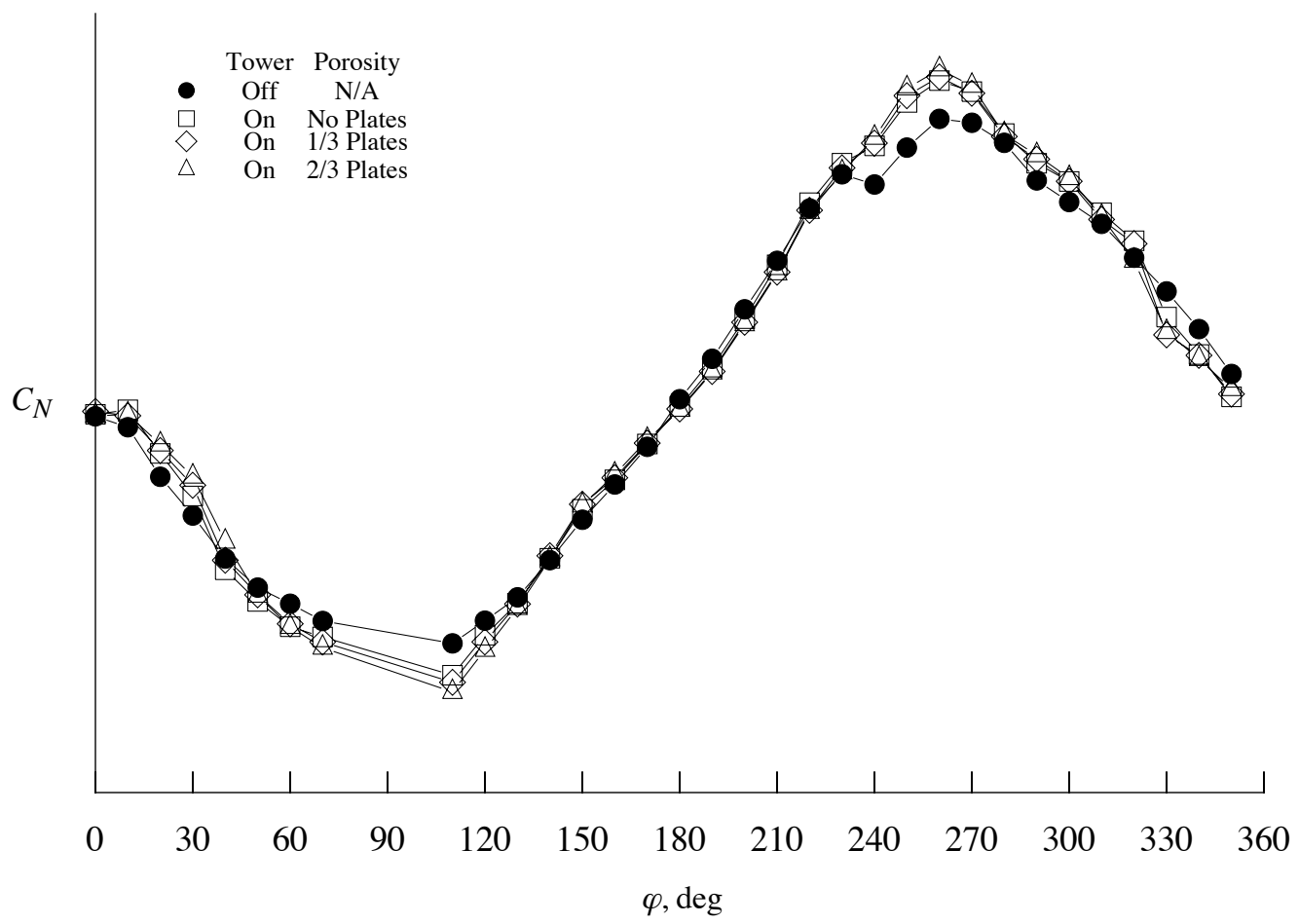

a. Normal force coefficient

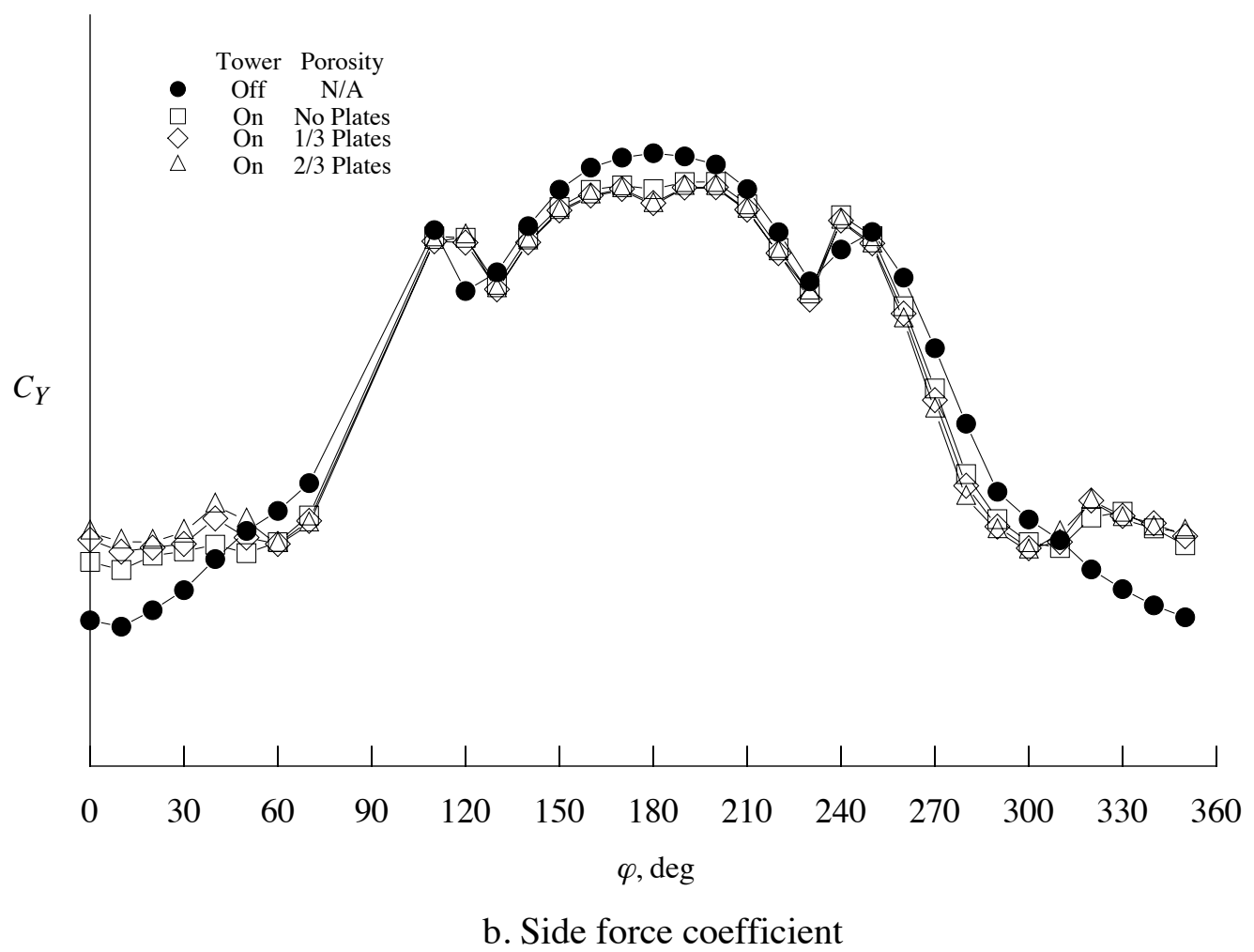

Figure 31. Effect of launch tower porosity Ares I $C_{N}$ and $C_{Y}, h / L=0.6, q=80 \mathrm{psf}$. 